\title{
Bioinspired Metal Nanoparticle: Synthesis, Properties and Application
}

\author{
Sujoy K. Das and Enrico Marsili \\ School of Biotechnology, Dublin City University, Dublin, \\ Ireland
}

\section{Introduction}

Nanomaterials with a characteristic dimension in the range of 1-100 nanometers $(\mathrm{nm})$ are at the leading edge of nanoscience and nanotechnology. In recent years nanomaterials, and specifically metal nanoparticles, have received particular interest in diverse field ranging from material science to biotechnology (Guo et al. 2005, Daniel and Astruc 2004, Huang et al. 2007). Although widespread interest in nanomaterials is recent, the concept was introduced over 40 years ago. Nanomaterials have actually been produced and used by humans for hundreds of years: for example, the beautiful ruby red colour of some glass is due to gold nanoparticles (AuNP) trapped in the glass matrix. In the decorative glaze known as luster, found on some medieval pottery, the special optical properties of the glaze arose from metallic spherical nanoparticles which were dispersed in the glaze in a random fashion. Michael Faraday in 1857 on his pioneering work "Experimental relations of gold (and other metals) to light" (Faraday, 1857) explain the properties of this glaze. Now with advances of science and technology, the morphology of this material, which contains metallic nanoparticles, has been understood. Because of extremely small size and high surface volume ratio of nanoparticles, the physicochemical properties of nanoparticles-containing materials are quite different to those of the bulk materials (El-Sayed 2001). Thus, nanomaterials have potential applications in electronics and photonics, catalysis, information storage, chemical sensing and imaging, environmental remediation, drug delivery and biological labelling (Guo et al. 2005, Daniel and Astruc 2004, Huang et al. 2007). It is well known that the optical, electronic, and catalytic properties of metal nanoparticles are greatly influenced by their size, shape, and crystal structure. For example, silver (Ag) and gold (Au) nanocrystals of different shapes possess unique optical scattering responses (Daniel and Astruc 2004, Roduner 2006). Whereas highly symmetric spherical particles exhibit a single scattering peak, anisotropic shapes such as rods, triangular prisms, and cubes exhibit multiple scattering peaks in the visible wavelengths due to highly localized charge polarizations at corners and edges (Mie 1908). Thus, synthesis of metal nanoparticles with defined morphology gained much interest. A variety of strategies have been developed for the synthesis of metal nanoparticles (MNPs) and nanomaterials. Optimizing the nanomaterial synthesis has now become a prolific area of investigation. In the first part of this chapter, we will review the synthetic methods for MNPs production, with particular regard to biosynthesis in viable organisms and protein extracts. In the second part, we will discuss the most recent finding on the biosynthetic mechanism, the properties of the nanobioconjugates, and recent applications of MNPs. 


\section{Synthesis of metal nanoparticles}

Synthesis of MNPs is carried out by several physical and chemical methods that include laser ablation (Mafuné et al. 2001), ion sputtering (Raffi et al. 2007), solvothermal synthesis (Rosemary, T. Pradeep 2003), chemical reduction (Chaki 2002), and sol-gel (Shukla and Seal 1999) method. Basically, there are two approaches for nanoparticle synthesis, the top-down and bottom-up. Top-down approaches seek to create nanoscale objects by using larger, externally-controlled microscopic devices to direct their assembly, while bottom-up approaches adopt molecular components that are built up into more complex assemblies. The top-down approach often uses microfabrication techniques where externally controlled tools are used to cut, mill, and shape materials into the desired shape and size. Micropatterning techniques, such as photolithography and inkjet printing are well known examples of top-down approach. On the other hand, bottom-up approaches use the self-assembled properties of single molecules into some useful conformation. Different commonly used physical and chemical methods are described in the following paragraphs.

\subsection{Laser ablation}

Laser ablation (Mafuné et al. 2001) enables to obtain colloidal nanoparticles solutions in a variety of solvents. Nanoparticles are formed during the condensation of a plasma plume produced by the laser ablation of a bulk metal plate dipped in a liquid solution. This technique is considered as a 'green technique' alternative to the chemical reduction method for obtaining noble MNPs. However, the main drawbacks of this methodology are the high energy required per unit of MNPs produced and the little control over the growth rate of the MNPs.

\subsection{Inert gas condensation}

Inert gas condensation (IGC) is the most widely used methods for MNPs synthesis at laboratory-scale. Gleiter (1984) introduced the IGC technique in nanotechnology by synthesizing iron nanoparticles. In IGC, metals are evaporated in ultra high vacuum chamber filled with helium or argon gas at typical pressure of few hundreds pascals. The evaporated metal atoms lose their kinetic energy by collisions with the gas, and condense into small particles. These particles then grow by Brownian coagulation and coalescence and finally form nano-crystals. Recent application of this technique includes size-controlled synthesis of $\mathrm{Au} / \mathrm{Pd}$ NPs (Pérez-Tijerina et al., 2008) and hetero-sized Au nanoclusters for non-volatile memory cell applications (Kang et al., 2011).

\subsection{Sol-gel method}

The sol-gel process is a wet-chemical technique developed recently in nanomaterial synthesis. The inorganic nanostructures are formed by the sol-gel process through formation of colloidal suspension (sol) and gelation of the sol to integrated network in continuous liquid phase (gel). Size and stability control quantum-confined semiconductor, metal, and metal oxide nanoparticles has been achieved by inverted micelles (Gacoin 1997), polymer blends (Yuan et al. 1992), block copolymers (Sankaran et al. 1993), porous glasses (Justus et al. 1992), and ex-situ particle-capping techniques (Olshavsky and Allcock 1997). However, the fundamental problem of aqueous sol-gel chemistry is the complexity of process and the fact that the as-synthesized precipitates are generally amorphous. In non-aqueous sol-gel 
chemistry the transformation of the precursor takes place in an organic solvent. The nonaqueous (or non-hydrolytic) processes are able to overcome some of the major limitations of aqueous systems, and thus represent a powerful and versatile alternative. The advantages are a direct consequence of the manifold role of the organic components in the reaction system (e.g., solvent, organic ligand of the precursor molecule, surfactants, or in situ formed organic condensation products). Nowadays, the family of metal oxide nanoparticles are synthesized by non-aqueous processes and ranges from simple binary metal oxides to more complex ternary, multi-metal and doped systems.

\subsection{Hydrothermal and solvothermal synthesis}

The hydrothermal and solvothermal synthesis of inorganic materials is an important methodology in nanomaterial synthesis. In hydrothermal method, the synthetic process occurs in aqueous solution above the boiling point of water, whereas in solvothermal method the reaction is carried out in organic solvents at temperatures $\left(200-300^{\circ} \mathrm{C}\right)$ higher than their boiling points. Though development of hydrothermal and solvothermal synthesis has a history of 100 years, recently this technique has been applied in material synthesis process. Normally, hydrothermal and solvothermal reactions are conducted in a specially sealed container or high pressure autoclave under subcritical or supercritical solvent conditions. Under such conditions, the solubility of reactants increases significantly, enabling reaction to take place at lower temperature. Among numerous examples, $\mathrm{TiO}_{2}$ photocatalysts were synthesized through hydrothermal process (Ren et al., 2007). Because of low cost and energy consumptiom, hydrothermal process can be scale-up for industrial production. Solvothermal process enables to choose among numerous solvents or mixture thereof, thus increasing the versatility of the synthesis. For example, well-faceted nanocrystals of $\mathrm{TiO}_{2}$ with high reactivity were synthesized in a mixture of the solvents Hydrogen fluoride (HF) and 2-propanol (Yang et al., 2008)

\subsection{Colloidal methods}

The crystallographic control over the nucleation and growth of noble-metal nanoparticles has most widely been achieved using colloidal methods (Tao et al. 2008, Turkevich et al. 1951, Frens 1972, Brust et al. 1994). In general, metal nanoparticles are synthesized by reducing metal salt with chemical reducing agents like borodride, hydrazine, citrate, etc., followed by surface modification with suitable capping ligands to prevent aggregation and confer additional surface properties. Occasional use of organic solvents in this synthetic process often raises environmental questions. At the same time, these approaches produce multi-shaped nanoparticles requiring purification by differential centrifugation and consequently have low yield. Thus, the development of reliable experimental protocols for the synthesis of nanomaterials over a range of chemical compositions, sizes, and high monodispersity is one of the challenging issues in current nanotechnology. In this context, current drive focused on the development of green and biosynthetic technologies in for production of nanocrystals with desired size and shape.

\subsection{Bio-inspired nanomaterial synthesis}

In keeping with global efforts to reduce generation of hazardous waste and to develop energy-effective production routes, 'green' chemistry and biochemical processes are progressively integrating with modern developments in science and technology. Hence, any 
synthetic route or chemical process should address the fundamental principles of 'green chemistry' by using environmentally benign solvents and nontoxic chemicals (Anstas and Warner 1998). The green synthesis of MNPs should involve three main steps based on green chemistry perspectives, namely (1) the selection of a biocompatible and nontoxic solvent medium, (2) the selection of environmentally benign reducing agents, and (3) the selection of nontoxic substances for stabilization of the nanoparticles. Employing these principles in nanoscience will facilitate the production and processing of inherently safer nanomaterials and nanostructured devices. Green nanotechnology (Dahl et al. 2007) thus aims to the application of green chemistry principles in designing nanoscale products, and the development of nanomaterial production methods with reduced hazardous waste generation and safer applications. Further, biochemical process can occur at low temperatures, because of the high specificity of the biocatalysts. Hence, a synthetic route that include one or more biological steps will result in consistent energy saving and lower environmental impact with respect to conventional methods. To optimize safer nanoparticle production, it would be desirable to employ bio-based methods, which could minimize the hazardous conditions of materials fabrication and use. Inspiration from nature, where living organisms produce inorganic materials through biological guided process known as biomineralization, is adopted as a superior approach to nanomaterials assembly (Mann 1993). The biomineralization processes exploit biomolecular templates that interact with the inorganic material at nanoscale, resulting in extremely efficient and highly controlled syntheses. Typical examples of biomineralized products include siliceous materials synthesized by diatoms and sponges, calcite or aragonite (calcium carbonates) in invertebrates, and apatite (calcium phosphates and carbonates) in vertebrates. These biominerals are the phosphate and carbonate salts of calcium that form structural entities such as sea shells and the bone in mammals and birds in conjunction with organic polymers. The structures of these biocomposite materials are highly controlled both at nano- and macroscale level, resulting in complex architectures that provide multifunctional properties. Simpler organisms, such as bacteria, algae, and fungi, have also developed during hundreds of millions of years of evolution highly specialized strategies for biominerals synthesis. The role of the templating molecule in biomineralization is to provide a synthetic microenvironment in which the inorganic phase morphology is tightly controlled by a range of low-range interactions. Typical example includes silicatein filament, protease-like proteins termed silicateins, from a marine sponge Thetya aurantia direct the polymerisation of silica and silicones from tetraethoxysilane in vitro. Figure 1A-F demonstrates that silicatein filaments serve as scaffolds to organize the deposition of the resulting silica and silsesquioxanes.

Diatoms are unicellular algae that have the extraordinary capability to produce an enormous variety of biosilicates structures. Each diatom species is characterized by a specific biosilicate cell wall that contains regularly arranged slits or pores in the size range between 10 and 1,000 nm (nanopatterned biosilica). An important component of biomineralization is the protein or peptide template that controls the shape and crystal structure of biominerals as well as the assembly procedure. Biosilica morphogenesis takes place inside the diatom cell within a specialized membrane-bound compartment termed the silica deposition vesicle. Silica formation from a silicic acid solution is catalyzed by biosilica-associated peptides (silaffins) and long-chain polyamines in diatoms (Fig. 1G-J). Other examples of inorganic, nanostructured biosynthetic minerals include $\mathrm{Fe}_{3} \mathrm{O}_{4}, \mathrm{CaSO}_{4}$, $\mathrm{BaSO}_{4}$, etc., which are synthesized by a variety of microorganisms. These minerals often 
have special uses such as magnetic sensors in magnetotactic bacteria $\left(\mathrm{Fe}_{3} \mathrm{O}_{4}\right)$, gravity sensing devices $\left(\mathrm{CaCO}_{3}, \mathrm{CaSO}_{4}, \mathrm{BaSO}_{4}\right)$ and iron storage and mobilization $\left(\mathrm{Fe}_{2} \mathrm{O}_{3} . \mathrm{H}_{2} \mathrm{O}\right.$ in the protein ferritin). Magnetotactic bacteria (Magnetospirillum magnetotacticum, Magnetobacterium bavaricum, Magnetospirillum gryphiswaldense) have special organelles called magnetosomes that contain magnetic crystals, which enable the cells to orient themselves along the magnetic field lines of the Earth. Magnetotactic bacteria synthesize magnetic particles comprising iron oxide $\left(\mathrm{Fe}_{3} \mathrm{O}_{4}\right)$, iron sulphides $\left(\mathrm{Fe}_{3} \mathrm{~S}_{4}\right)$, or both in their intracellular compartment. The magnetic particles are aligned in chains within the bacterium, and function as biological compass needles. This enables the bacterium to migrate along oxygen gradients in aquatic environments under the influence of the Earth's geomagnetic field. Fig. 2 depicts the formation of magenite in M. magnetotacticum and M. Gryphiswaldens and also orientation of isolated magnetosome particles under the magnetic field.
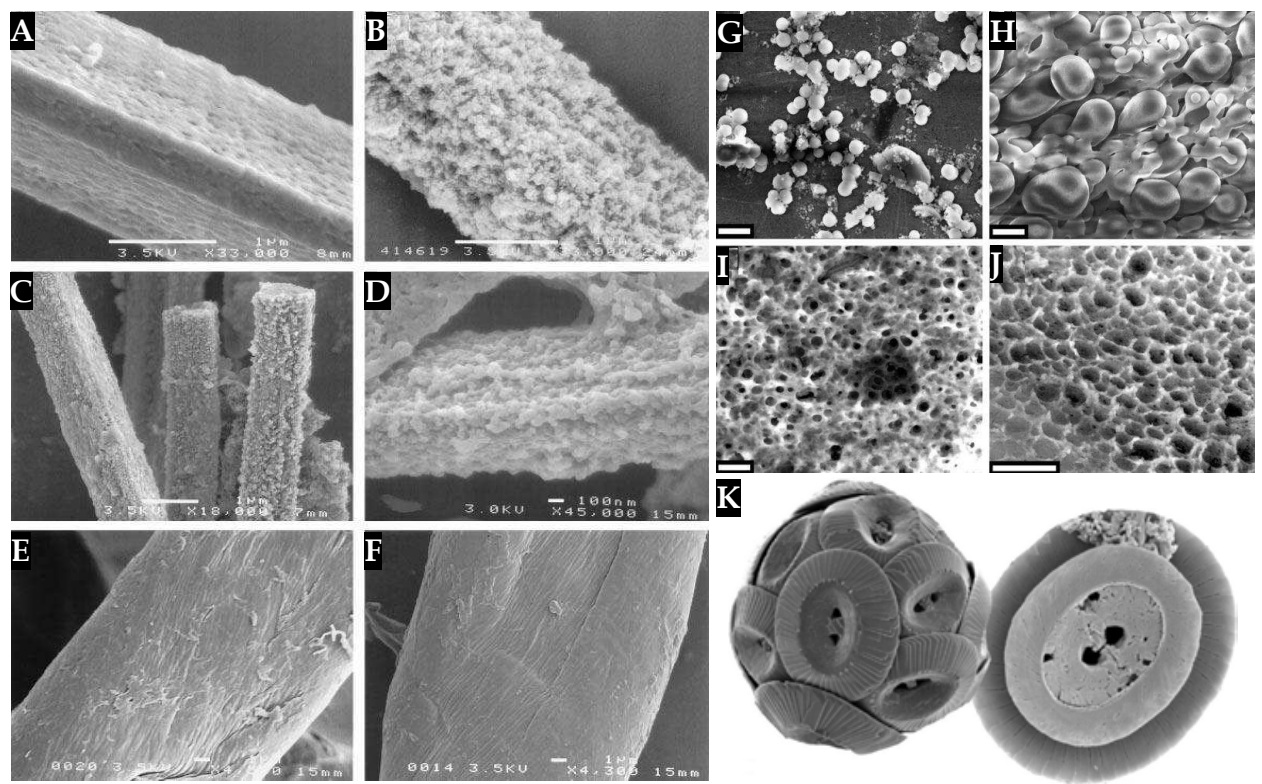

Fig. 1. SEM images of the products of the reaction between silicon alkoxides and silicatein or cellulose filaments. (A) Silicatein filaments before the reaction. (B) Silicatein filaments after a 12-h reaction with TEOS $(1.0 \mathrm{ml} ; 4.5 \mathrm{mmol})$ plus Trisz- $\mathrm{HCl}$ buffer. $(C)$ Air-dried silicatein filaments incubated with TEOS as in $B$, but with no additional water. $(D)$ Silicatein filaments after an 8 -h reaction with phenyltriethoxysilane $(1.0 \mathrm{ml} ; 4.1 \mathrm{mmol})$ plus TriszHCl buffer. (E) Cellulose fiber. $(F)$ Cellulose fiber after a 12-h reaction with TEOS as in B. Proc. Natl. Acad. Sci. USA. 1999, 96, 361-365. SEM analysis of silica precipitates formed by mixtures of natSil-1A and natSil-2. $(G)$ natSil-2 at 0.5 units $/ \mu 1$, natSil-1A at $0.3 \mathrm{mM}$. $(\mathrm{H})$ natSil-2 at 5.0 units/ $\mu \mathrm{l}$, natSil-1A at $0.3 \mathrm{mM}$. (I) natSil-2 at 2.0 units/ $\mu \mathrm{l}$, natSil-1A at $0.3 \mathrm{mM}$. (J) natSil-2 at 1.6 units/ $\mu \mathrm{l}$, natSil-1A at $0.2 \mathrm{mM}$. Proc. Natl. Acad. Sci. USA. 2003, 100, 12075-12080. SEM micrographs of coccosphere (K) showing their morphology and the composite nature. 


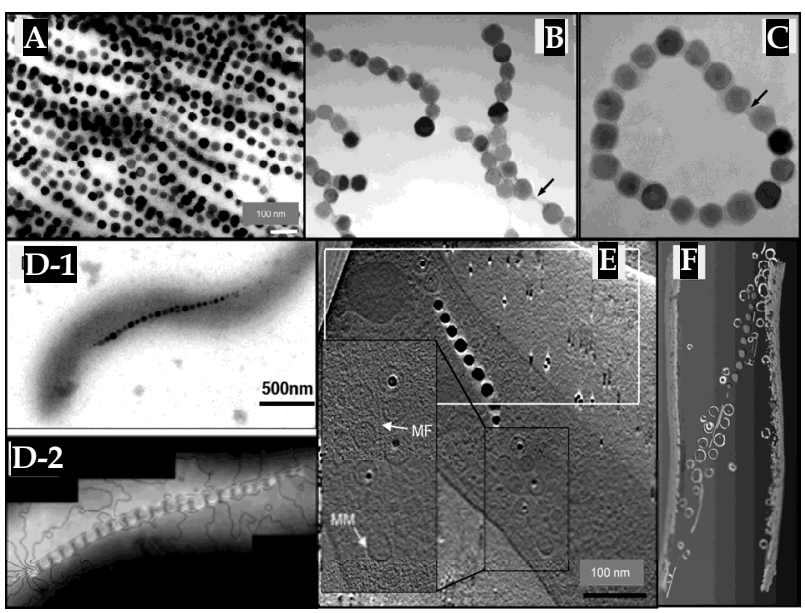

Fig. 2. Isolated magnetosome $(\mathrm{A}-\mathrm{C})$ particles form straight chains in weak ambient magnetic fields (A) but form bent chains (B) or flux-closure rings in zero fields (C). Magnetic microstructure (D) of a magnetosome chain. TEM bright-field image (D-1) of a single bacterial cell of Magnetospirillum magnetotacticum. Magnetic induction map (D-2) recorded using off-axis electron holography from the magnetosome chain of the same cell as shown in part D-1. Cryoelectron tomography image (E) shows organization of the magnetosome chain and the cytoskeletal magnetosome filament (MF) in Magnetospirillum gryphiswaldense, and Tomographic reconstruction (F) of a magnetic cell. Chem. Rev. 2008, 108, 4875-4898.

Desulfovibrio magneticus, a dissimilatory sulphate-reducing bacterium, produces unique irregular bullet-shaped magnetite. Formation of extracellular magnetic iron sulphide (Sakaguchi et al. 1993) and intracellular hematite (Posfai et al. 2006) by this bacterium has also been reported. The molecular mechanism of bacterial magnetite biomineralization is very complex and occurs in multistep process. Recent genome, proteome and transcriptome studies revealed that proteins located on the magnetosomial membrane are the key components in biomineralization process.

The natural occurrence of inorganic nanomaterials in microorganisms encourages the use of microorganisms as possible eco-friendly nanofactories for nanoparticle synthesis routes alternative to chemical methods. The metal reduction potential of several bacteria, yeast, and fungi has been known for at least 20 years. Microorganisms such as dissimilatory metal reducers and sulphate reducers play a key role in metal biogeochemistry and have been used with a certain success in metal bioremediation of contaminated subsurface environments. The microbial based biosynthetic process for nanoparticle production is a relatively new and largely unexplored area of research. In recent past, prokaryotic microorganisms such as bacteria and actinomycetes, as well as algae, yeast, and fungi (eukaryotes) have been employed in the biosynthesis of metal nanoparticles. In the next section we will review in details MNPs biosynthesis in microorganisms.

\subsubsection{Bacterial nanoparticle synthesis}

Bacteria play a crucial role in metal biogeochemical cycling and mineral formation in surface and subsurface environments (Lowenstam 1981, Southam and Saunders 2005). In presence of high concentration and even toxic metal ions, bacteria harbour numerous detoxification 
mechanisms like dissimilatory oxidation or reduction of metal ions, complexation and/or precipitation, impaired transport system, efflux system, etc (Mergeay et al. 2003). Thus microorganisms have been used with a certain success in metal bioremediation of contaminated subsurface environments. However, their role in nanoparticle synthesis has recently been observed. Among the microorganisms, prokaryotic bacteria have received the most attention in the area of metal nanoparticle biosynthesis. The formation of extracellular and intracellular metal nanoparticles by bacteria like Escherichia coli, Pseudomonas stutzeri, Pseudomonas aeruginosa, Plectonema boryanum, Salmonells typlus, Staphylococcus currens, Vibrio cholerae, etc., have been reported (Klaus et al. 1999, Konishi 2004, Beveridge and Murray 1980, Southam and Beveridge 1994). Marine $\mathrm{Fe}^{+3}$ reducing bacterium Shewanella algae reduces $\mathrm{Au}^{+3}$ ions in anaerobic environments. In the presence of $S$. algae and hydrogen gas, $\mathrm{Au}$ ions are completely reduced and 10-20 nm AuNPs are formed (Konishi et al. 2004). The formation of AuNP was indicated by the change in reaction mixture, which turned to light yellow after $1 \mathrm{~h}$. The AuNPs were synthesized adopting similar procedure using two Pseudomonas aeruginosa isolates (Husseiny et al. 2007). The synthesis of stable gold nanocubes by the reduction of aqueous $\mathrm{AgCl}_{4}{ }^{-}$solution by Bacillus licheniformis was reported by Kalishwaralal et al. (2009). Biofilm formation of gram-negative $\beta$-proteobacterium Cupriavidus metallidurans is very common on Au grains. The isolated C. metallidurans from soils and sediments from temperate and tropical Australian sites interacted with $\mathrm{Au}^{+3}$ ions and form AuNPs distributed homogenously throughout cell wall (Reith 2009). The reduction of $\mathrm{Au}^{+3}$ complexes by $C$. metallidurans to AuNPs occurred through fast accumulation leading to the formation of intermediate $\mathrm{Au}^{+1}-\mathrm{S}$ complexes followed by a slow biochemically-driven reduction and intra- and extracellular deposition of AuNPs (Fig. 3).
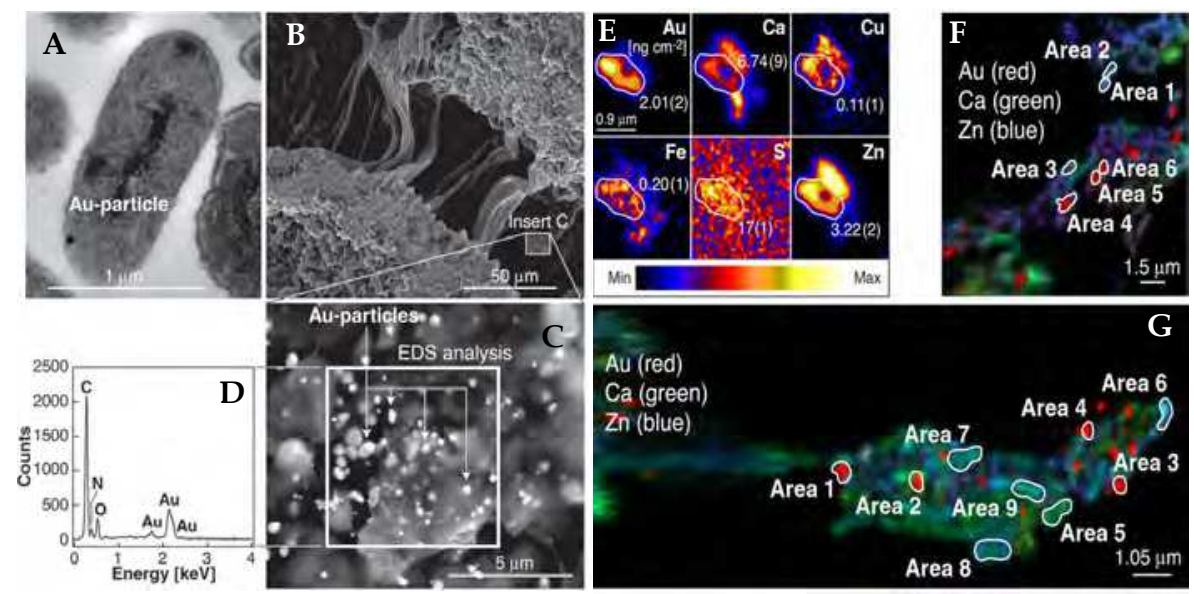

Fig. 3. TEM image of ultra-thin section $C$. metallidurans cell demonstrating formation of AuNPs in the periplasmic space $(A)$. SEM image $(B$ and $C)$ with energy dispersive $X$-ray analysis (SEM-EDXA) $(D)$ of a biofilm containing particulate $\mathrm{Au}(C)$ growing on $\mathrm{Au}$ grain from the Prophet Gold Mine, Australia. $\mu$ XRF maps (E) showing the distribution of $\mathrm{Au}, \mathrm{Ca}$, $\mathrm{Cu}, \mathrm{Fe}, \mathrm{S}$, and $\mathrm{Zn}$ in an $\mathrm{C}$. metallidurans cell following 1 min exposure to $\mathrm{Au}^{+3}$ at $\mathrm{pH}$ 7.0. Overlay false colour quantitative $\mu$ XRF maps (F-G) of the distribution of $\mathrm{Au}$ (red), Zn (blue), and $\mathrm{Ca}$ (green) in cell clusters after $72 \mathrm{~h}(\mathrm{~F})$ and $144 \mathrm{~h}(\mathrm{G})$ of incubation at pH 7.0. Proc. Natl. Acad. Sci USA. 2009, 160, 17757-17762. 
In brief, following adsorption of $\mathrm{Au}^{+3}$ complexes on cell surfaces, they reduced to $\mathrm{Au}^{+1}$ because of the high redox potential of $\mathrm{Au}^{+3}$ complexes [e.g., $\mathrm{E}_{0}=1.002 \mathrm{~V}$ for the reaction $\left.\mathrm{AuCl}_{4}^{-}+3 \mathrm{e}^{-}=\mathrm{Au}(\mathrm{s})+4 \mathrm{Cl}^{-}\right]$. This results in the induction of oxidative stress due to transfer of electrons from suitable electron donors in the cell to $\mathrm{Au}^{+3}$ ions and ultimately results in the upregulation of oxidative stress response genes. The resulting $\mathrm{Au}^{+1}$-complexes readily associated with nonpolar soft bases like $S$, present in membrane and periplasmic proteins and formed $\mathrm{Au}^{+1}-\mathrm{S}$ species. The resulting $\mathrm{Au}^{+1}-\mathrm{S}$ species reduced to $\mathrm{Au}^{0}$ in a slower reductive pathway. The AuNPs were also synthesized on the surface of Rhodopseudomans capsulate by interaction bacterial cells with $\mathrm{HAuCl}_{4}$ solution (He et al. 2007). The aqueous chloroaurate ions were reduced after $48 \mathrm{~h}$ of incubation and transformed to AuNPs. The $\mathrm{pH}$ value of the solution controlled the shape of AuNPs. The aqueous chloroaurate ions bound on the bacterial cell surface by interacting with different positively charged cell surface function groups such as amino, sulfhydryl and carboxylic. The electrons were then transferred from NADH by NADH-dependent reductase and reduced $\mathrm{Au}^{+3}$ to $\mathrm{Au}^{0}$.
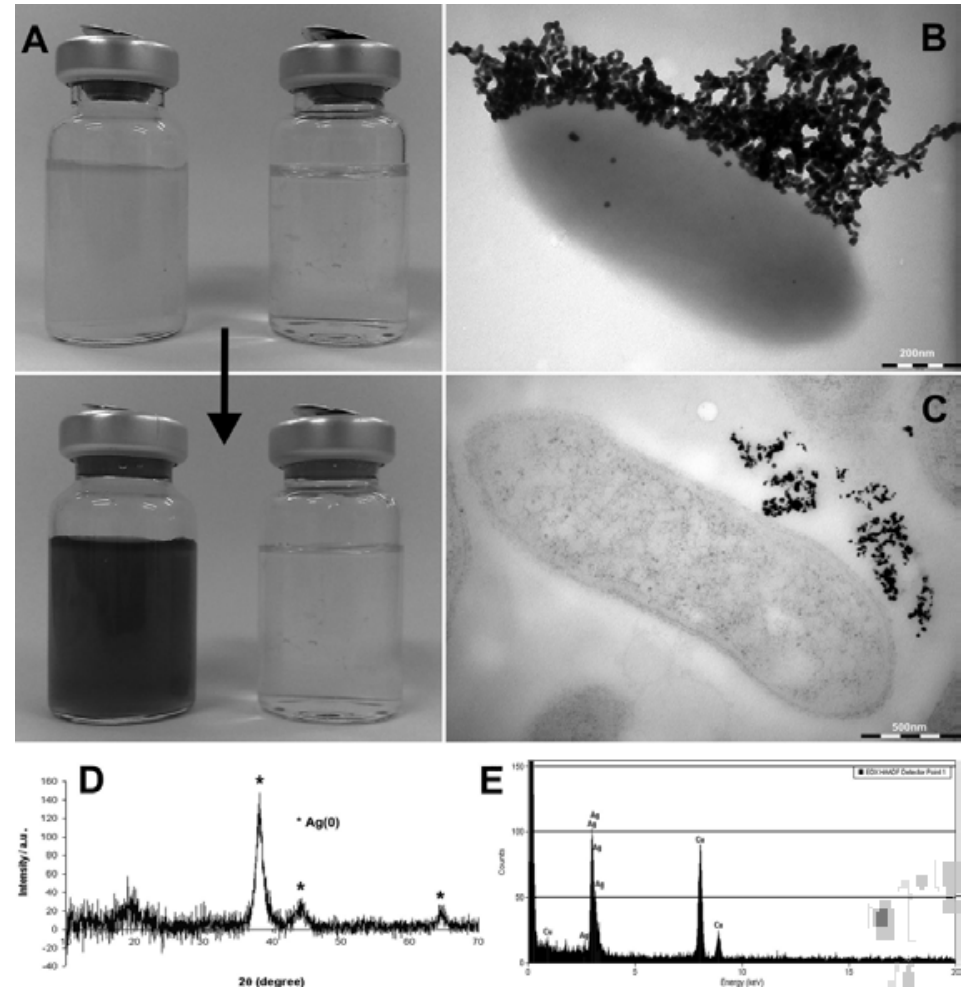

Fig. 4. Reduction of $200 \mu \mathrm{M} \mathrm{Ag}+1$ by late-exponential-phase cultures of G. sulfurreducens. (A) Cultures (top left) and spent supernatant (top right) before addition of $\mathrm{Ag}^{+1}$ and 2-min incubation (bottom) in the dark after addition of $\mathrm{Ag}^{+1}$. TEM of whole-mount (B) and ultrathin (C) section. (D) XRD profile of the cells and black precipitate, confirming the formation of $\mathrm{Ag}^{0}$. (E) EDAX spectrum of extracellular precipitates from unstained sectioned samples. Appl. Environ. Microbiol. 2008, 74, 7090-7093. 
Several bacterial strains cells are also known to synthesize silver nanoparticles (AgNPs) in a similar manner to that of AuNPs biosynthesis. P. stutzeri AG259 isolated from a silver mine reduced $\mathrm{Ag}^{+}$ions and formed AgNPs within the periplasmic space. The obtained AgNPs have well defined size and morphology, ranging from few $\mathrm{nm}$ to $200 \mathrm{~nm}$ or more. The supernatant of gram positive, thermophilic bacterium Bacillus licheniformis synthesized AgNPs in the range of $50 \mathrm{~nm}$ (Kalishwaralal et al. 2008). Formation of nanoscale elemental silver sarticles through enzymatic reduction was reported in Geobacter sulfurreducens (Law et al. 2008). The AgNPs formation is indicated by the change in colour of the silver nitrate reaction mixture, which gradually changed from yellow to brown. The extracellular precipitation of the nanoscale $\mathrm{Ag}^{0}$ was observed in G. sulfurreducens planktonic cells (Fig.4). C-type cytochromes are involved in the transferring the electrons to metal ions, thus reducing $\mathrm{Ag}^{+1}$ ions to $\mathrm{Ag}^{0}$. X-ray powder diffraction (XRD) and EDAX analysis confirmed that the obtained black precipitate was composed of AgNPs.

Kalimuthu and coworkers (2008) studied AgNPs synthesis using bacteria B. licheniformis, isolated from sewage collected from municipal wastes, and ultrasonically lysed bacterial cell. The synthesized AgNPs had average particle size of around $50 \mathrm{~nm}$. Recently, a rapid method for synthesizing small (1-7 nm) monodiperse AgNPs has been described by electrochemically active biofilm (EAB) using sodium acetate as an electron donor (Kalathil et al. 2011). Electrochemically active biofilm was formed by dipping a carbon paper into a mineral salt medium containing sodium acetate. The electrode was then mounted in a conventional microbial fuel cell. Anaerobic sludge was added under strict anaerobic conditions. Following successive medium changes and washing, EAB was formed on carbon paper after a week. Under strict anaerobic conditions, interaction of $\mathrm{EAB}$ with $\mathrm{AgNO}_{3}$ as precursor and sodium acetate as electron donor resulted in the synthesis of AgNPs. The XRD pattern demonstrated four characteristic peaks at $2 \theta$ values of $38^{\circ}, 46.33^{\circ}, 64.58^{\circ}$ and $77.24^{\circ}$, which correspond to the 111, 200, 220 and 311 planes of face-centered cubic (fcc) silver, respectively.

\subsubsection{Fungi in nanoparticle synthesis}

The fungal mediated MNP synthesis is a relatively recent research area. Compared to bacteria, fungi hold good promises for large scale nanoparticles production because they secrete large amounts of the enzymes involved in the MNP biosynthesis and are simpler to grow both in the laboratory and at industrial scale. Different fungal and actinomycete species, i.e. Fusarium oxysporum, Verticillium sp., Thermomonospora sp., Rhodococcus sp., and Rhizopus oryzae have been reported to synthesize nanoparticles intra- or extracellularly (Ahmad et al. 2003, Mandal et al. 2006). The biomass of Verticillium turned to purple color following exposure to $10^{-4} \mathrm{M} \mathrm{HAuCl}_{4}$ solution. This indicates the formation of AuNP (Mukherjee et al. 2001a) as confirmed by UV-visible absorption spectroscopy. The spectrum recorded from the gold-loaded biomass exhibited a SPR band at $\sim 550 \mathrm{~nm}$. However, this resonance band was not observed in the control biomass not exposed to gold ions. TEM analysis of the thin sections of the post treated cells clearly showed the intracellular formation of AuNPs. High resolution TEM image demonstrated that AuNPs with $20 \pm 8 \mathrm{~nm}$ average size are formed both on the cell wall and in the cytoplasmic membrane of the fungal cell. Further, the powder diffraction pattern indicated the crystalline nature of AuNPs. The Bragg reflection was characteristic of face centered cubic (fcc) gold structure. 
The exposure of Verticillium sp. to silver ions resulted in a similar intracellular growth of silver nanoparticles (AgNPs) (Mukherjee et al. 2001b). The intracellular formation mechanism of AuNPs and AgNPs has not been understood. However, it has been postulated that the gold and silver ions initially bind on the fungal cell surface through electrostatic interaction. The adsorbed metal ions are then reduced by enzymes present in the cell wall, leading to the formation of the metal nuclei, which subsequently grow through further reduction of metal ions. Absar and coworkers (2005) reported the extra- and intracellular biosynthesis of AuNPs by fungus Trichothecium sp. They observed that Trichothecium sp. reacted with gold ions during stationary phase and forms extracellular AuNPs of various morphologies, such as spherical, rod-like and triangular. However, under shaking conditions, the same fungal biomass forms intracellular AuNPs under shaking conditions. It was postulated that under shaking condition fungi secretes enzymes and proteins into the medium, however in shaking conditions these enzymes and proteins are not being released, thus resulting in the formation of extracellular or intracellular AuNP, respectively. Fungal templates has been used for noble-MNP synthesis (Bigall et al. 2008). Fungal cells were grown in presence of AuNP. Growth of a variety of fungi, such as Penicillium citreonigrum, Trametes versicolor, Fusarium sp., Phanaerochaete crysosporium, Trichoderma viride, Neurospora crassa, Nematolona frowardii, and Bjerkandera adusta was tested in citrate-stabilized colloidal medium containing different noble-metal nanoparticles. All these fungi grow well in the as-prepared gold, silver, platinum, and palladium nanoparticle solutions. Decoration of the fungal surface with MNPs (Fig. 5) takes place without any further functionalization. The metal nanoparticles bind on the surface of the fungi and forms nano-hybride system. Supercritical drying of these structures conserves the threedimensional tubular shape.

The extracellular synthesis of AgNPs by a marine fungus Penicillium fellutanum, isolated from costal mangrove sediment, has been described by Kathiresan and co-workers (2009). They adopted a similar biosynthetic procedure to that described earlier. The synthesis of AgNPs in the reaction mixture was confirmed by the absorption peak at $430 \mathrm{~nm}$. The particles had spherical shape with size ranging from 5 to $25 \mathrm{~nm}$. The extracellular synthesis of stable AgNPs using the fungus Penicillium brevicompactum WA 2315 was demonstrated by Shaligram et al. (2009). The nanoparticles was obtained by incubating silver ions with the fungus supernatant for $72 \mathrm{~h}$. TEM analysis showed that the average size of nanoparticles was $58.35 \pm 17.88 \mathrm{~nm}$. The FTIR spectrum of the freeze-dried powder AgNPs sample formed showed band at $3356 \mathrm{~cm}^{-1}$ and $2922 \mathrm{~cm}^{-1}$, which were assigned to the stretching vibration of primary and secondary amines, respectively. The bands at $1622 \mathrm{~cm}^{-1}$ and $1527 \mathrm{~cm}^{-1}$ correspond to the stretching vibration of primary and secondary amines. The two bands at $1412 \mathrm{~cm}^{-1}$ and $1029 \mathrm{~cm}^{-1}$ were assigned to the $\mathrm{C}-\mathrm{N}$ stretching vibrations of aromatic and aliphatic amines. This FTIR spectrum supports the involvement of proteins in the biosynthesis mechanism of AgNPs. Extracellular aromatic compounds such as naphthoquinones and anthraquinones act as electron shuttle in silver ions reduction as they have excellent redox properties.

The fungi morphology was different following binding with MNPs. The mycelia and spore in gold binding fungi (E07AS) was visible in both secondary electron and backscattering image, however, the spore and mycelia is almost invisible in the gold sensitive backscattering mode in the fungus O07AS (Fig. 5C-F). Though all the fungi tested grew in presence of metal nanoparticles, they had different affinity for different MNPs. Most of the fungi grew best in gold, followed by platinum and palladium NP solutions. Growth of fungi in AgNPs solution only occurred in the case of B. Adusta due to toxic effect of silver. 


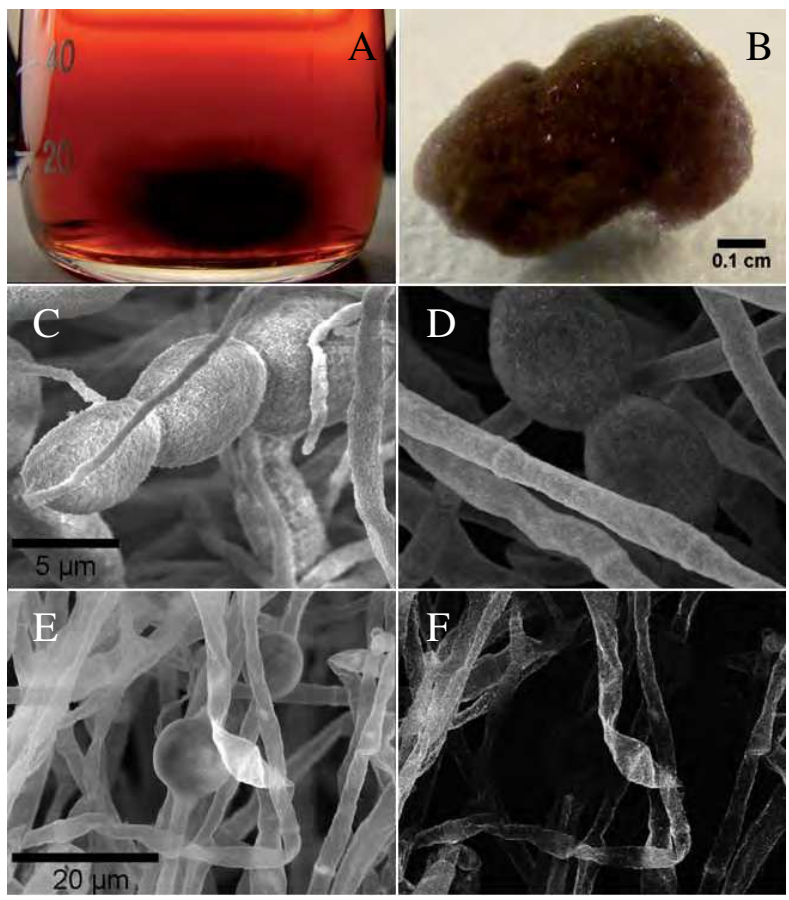

Fig. 5. Color photographs of a gold-Penicillium citreonigrum hybrid structure in a gold nanoparticle solution (A), and after critical point drying (B). Scanning electron micrographs (C-F) of similar regions within a hybrid structure (left: secondary electron mode, right: backscattering mode). The spores of the fungus E07AS (C-D) show significant assembly of AuNP, whereas the spores of the fungus O07AS (E-F) do not. Angew. Chem. Int. Ed. 2008, $47,7876-7879$.

It was also reported (Duran et al. 2005) that the enzyme hydrogenase is present in a filtrate broth obtained from Fusarium oxysporum growth. Thus, the silver nanoparticles production capacity is likely to be a result of the interaction between reductases and electron shuttle.

A single pot green chemical synthesis of AuNP by fungal strain Rhizopus oryzae has been reported by Das et al. (2009). R. oryzae synthesize AuNP on the mycelial surface, which exhibited SPR band at $540 \mathrm{~nm}$. HRTEM image demonstrated formation of monodisperse gold nanoparticle with average size of $10 \mathrm{~nm}$ on the surface of the mycelia. FTIR study demonstrated that gold ions initially bound through electrostatic interaction with functional groups of proteins present on the surface of the mycelia, then got reduced to AuNPs. The surface bound protein molecules act both as reducing and as stabilizing agents. The extremophilic actinomycete, Thermomonos Sp. reduced the gold ions extracellularly, yielding ANPs (Sastry et al. 2003). Even the edible mushroom Volvariella volvacea can produce Au and Ag NPs through metal reducing compounds. The mushroom was boiled initially in water and then filtered. The filtrate was cooled to room temperature and used as reducing agent for AuNPs synthesis. Following reduction purple colored AuNPs was formed. The mushroom biomass also prevents NPs aggregation after their formation (Philip 2009). 


\subsubsection{Mechanism of nanoparticle synthesis}

Synthesis of metal nanoparticles in different types of microbial species are reported, however, the exact mechanism of nanoparticle biosynthesis has not been established. The complex interaction process along with metabolic complexity of viable microorganisms complicates the analysis and identification of active species in the nucleation and growth of metal NPs. The elucidation of the biochemical pathways leading to gold biomineralization is necessary to develop a rational approach to NP biosynthesis. A number of issues need to be addressed from the nanotechnology and microbiological points of view before such biosynthetic procedures can compete with the conventional protocols. An important component of biomineralization is the protein or peptide template that controls the shape and crystal structure of biominerals as well as the assembly behavior. Thus the underlying mechanism can be applied in the synthesis of technologically important materials beyond those few existing biominerals in nature. Recent works by Xie et al. (2007) demonstrated that proteins are the principal biomolecules involved in the algal synthesis of gold NPs. Enzymatic reduction (Ahmad et al. 2003; He et al. 2007) of metal ions and subsequent growth of metal nanoparticles have postulated for fungal mediated synthetic mechanism. Ahmad et al. (2003) postulated that in Fusarium oxysporum, a NADH-dependent reductase is involved in AgNPs synthesis. Daniel et al. (2008) demonstrated that the FAD-dependent enzyme glutathione reductase (GR) catalyzes the NADPH-dependent reduction of $\mathrm{AuCl}_{4}$. The synthesized AuNPs at the active site tightly bound through the catalytic cysteines group. Involvement of nitrate reductase in B. licheniformis in the fabrication of nanoparticles has also been reported. It has been postulated that NADH dependent nitrate reductase is an important factor in the biosynthesis of metal nanoparticles. However, the biochemical mechanism of metal ion reduction and subsequent NP formation remains unexplored.

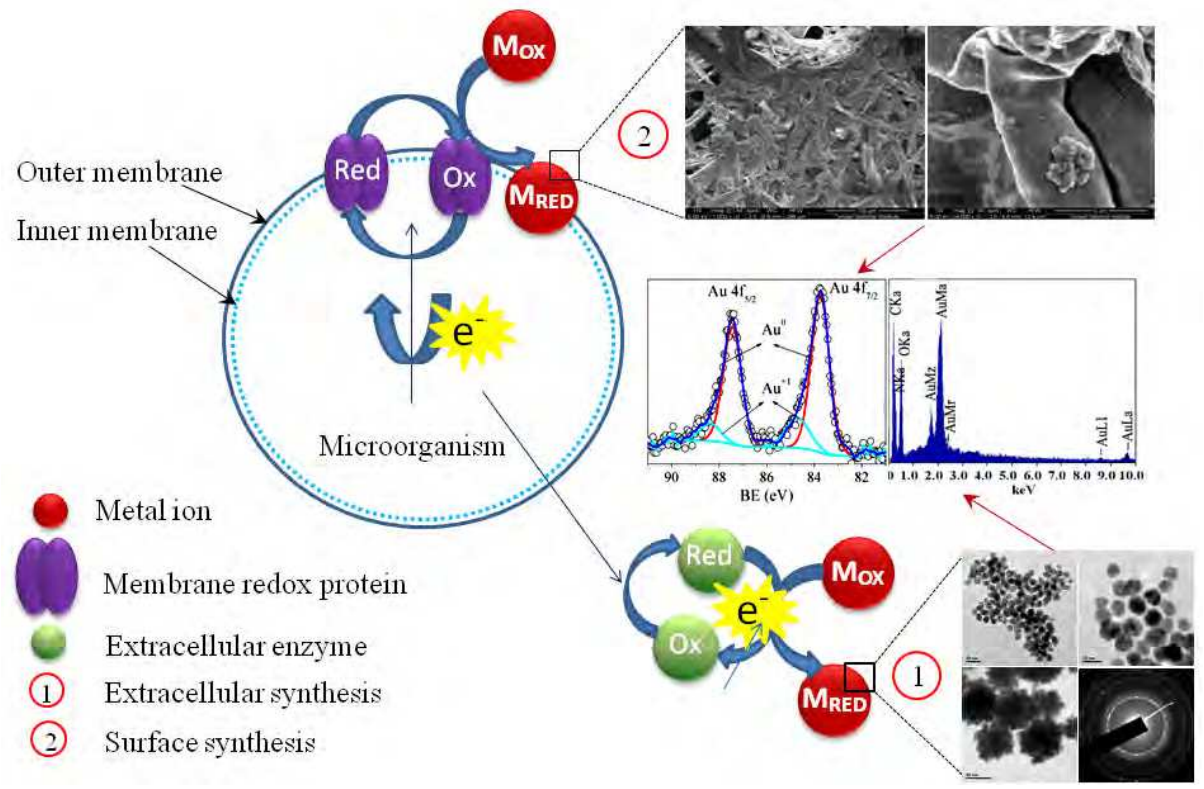

Fig. 6. Proposed mechanism of AuNP synthesis in Rhizopus oryzae (Rev. Environ. Sci. Biotechnol. 2010, 9, 199-204). 
In recent research investigation on biosynthesis of AuNPs, we observed through TEM analysis that AuNPs are synthesized both in cytosolic portion as well as cell wall of R. oryzae (Unpublished data). Different surface protein(s) as well as cytosolic protein(s) have been extracted from whole mycelia and used for AuNPs synthesis. Based on protein induction and also through SDS-Gel electrophoresis experiment we hypothesized that both cytosolic and surface protein(s) of $R$. oryzae are involved in AuNPs synthesis (Fig. 6). X-ray photoelectron spectroscopy (XPS) and FTIR study demonstrated that protein(s) following reduction of gold ions bonded with the AuNPs and formed bioconjugate system. The identification of specific protein and or peptides molecules responsible for nanoparticle synthesis will broaden the possible application of biomineralization in nanoparticle process scale up.

\section{Properties of metal nanoparticles}

The physicochemical properties of the metal nanoparticle are completely different to that of the bulk material due to their very small size and high surface to volume ratio. While the properties of bulk materials are solely composition-dependent, as the size of the particles decreases to few $\mathrm{nm}$, the the electronic structure is altered from the continuous band to discrete electronic levels Thus, the properties of the nanomaterial become size-dependent (Burda et al. 2005). In a small nanoparticles, a large fraction of the atoms will be on the surface. The atoms on the surface are chemically more active compared to the bulk atoms, because they usually have feweradjacent coordinate atoms and unsaturated sites. A striking properties deriving from the increasing surface energy of nanomaterials is the decrease of melting point. Further, the overlapping of different grain sizes affects the physical strength of the material. Also, when the crystallites of a material are reduced to the nanometer scale, there is an increase in the role of interfacial defects: grain boundaries, triple junctions, and elastically distorted layers. The long established Hall-Petch model (2005), that shows the inverse relationship between grain size and material yield strength, has been proven to hold with nanoparticles as well. A study of nanocrystalline Fe powder revealed that when grain size was decreased from $33 \mathrm{~nm}$ to $8 \mathrm{~nm}$, hardness increased and fracture stress and elongation to failure decreased.

Hall Petch Model:

$$
\sigma_{y}=\sigma_{o}+\frac{K}{\sqrt{d}}
$$

(yield strength determined by a constant $K$ and the mean grain size, $d$ )

These results can be connected to the reduction of defects in the material such as micropores and other flaws (Andrievski and Glezer 2000).

Similarly, the yellow colored noble metal gold is known as a shiny, has a face centred cubic structure, is non-magnetic and melts at $1336 \mathrm{~K}$. However, $10 \mathrm{~nm}$ gold particles is quite different, absorb green light and thus appear red. The melting temperature decreases dramatically as the size decreases. It is interesting to note that scientists have been using nanoparticles in tires for a very long time but without knowing the reason, besides that it turned the rubber black. For years, engineers have added carbon black nanoparticles in the rubber of tires to improve the quality. The addition of carbon black increases the strength and tensile properties, tear and abrasion resistance, and increased hardness because of the integration of carbon grains (Maiti et al. 2005). It has been found that with increased 
amounts of carbon black in the rubber compounds, the absolute strength initially increases because of reinforcement from the carbon grains but then decreases due to the dilution effect. The improved reinforcement results by the carbon black particles can be explained by exfoliation, intercalation, dispersion, and occlusion which are essentially the interactions of the grains with the material.

\subsection{Optical properties}

The Localized Surface Plasmon Resonance (LSPR) is referred as free to oscillation of electrons in the conduction band of metals upon excitation with incident radiation (El-Sayed 2001, Murphy et al. 2005 and reference therein). However, for nanoscale metals, the oscillation distance is restricted by the size of nanoparticle. For gold and silver nanoparticles, LSPR corresponds to photon energies in the visible wavelength regime, giving rise to significant interest in their optical properties. These optical characteristics include strong plasmon absorption, resonant Rayleigh scattering, and localized electromagnetic fields at the nanoparticle surface. The size, shape, and dielectric constant of the surrounding medium of nanoparticle strongly influence the Plasmon absorption. For instance, spherical gold and silver nanoparticles have single plasmon absorption bands at $\sim 540$ and $\sim 400 \mathrm{~nm}$, respectively. However, anisotropic gold and silver nanorods exhibit two principle plasmon absorption bands (Kelly et al. 2003); one at shorter wavelength corresponding to absorption and scattering of light along the short axis of the nanorod (transverse plasmon band), and the other band at longer wavelength corresponding to absorption and scattering of light along the long axis of the nanorod (longitudinal plasmon band). The longitudinal plasmon absorption bands are tunable with nanorod aspect ratio from the visible to the near-IR.

The excellent light-scattering properties of gold nanorods are sensitive to their orientation and Murphy and Orendorff (2005) used this property to determine the nanorod orientation in polymer films. The plasmonic AuNP have been used for sensing, imaging and Surface Enhanced Raman Scattering (SERS) detection. The light scattering properties of nanoparticle has been used in dark field microscopy to detect the uptake nanoparticles by cells (Maier 2007). Sometimes the combined dark field microscopy with the shifts associated with local dielectric constant changes used for analyte detection.

Inelastic visible light scattering from metal nanoparticles is also a useful means to gain chemical information about the nanoparticle's environment. SERS is a powerful analytical tool for determining chemical information for molecules on metallic substrates on the 10$200 \mathrm{~nm}$ size scale. Though the Raman vibrations of molecules are very weak, in presence nanoparticle the molecular Raman vibrations are enhanced by orders of magnitude. As SERS substrates colloidal nanoparticles are of special interest not only because of their strong light scatterering property but also their tunable optical properties, which depend on nanoparticle size, shape, and aggregation state. The largest surface enhancements, that seemingly lead to single molecule SERS, are observed for molecules adsorbed in the fractal space at junctions between nanoparticles, referred to as 'SERS hot spots'. This is a result of localized surface plasmon (LSP) coupling between nanoparticles and the enhanced electromagnetic field intensity localized at nanoparticle junctions. Anisotropic metallic nanoparticles have all of the characteristics that make them excellent candidates as SERS substrates. Plasmon absorption bands can be tuned with nanocrystal aspect ratio to be in resonance with common visible laser sources. 


\subsection{Properties of nanoparticle-biomolecule hybrid systems}

The development of hybrid nanomaterials that incorporate the highly selective catalytic and recognition properties of biomaterials, such as enzymes, with the unique properties of nanoparticles, result in flexible building blocks for biosensors and drug delivery. In fact, these construct are the forefront of the developing bionanotechnology research. However, the understanding of these complex assemblies is still incomplete, and the modelling still inadequate to describe their behaviour (Katz and Willner 2004 and reference therein). The functionalization of NPs with biomolecules results in changes in the properties of the NPs and their interactions with the environment. Upon adsorption of vitamin $\mathrm{C}$ on $\mathrm{TiO}_{2} \mathrm{NPs}$, the optical properties of the particles were red-shifted by $1.6 \mathrm{eV}$ as a result of charge transfer that originates from the specific binding of the electron-donating modifier to corner defects on the surface of the nanoparticles. The solubility of NPs in water can be greatly improved by the functionalization of their surfaces with highly hydrophilic biomolecules.

Furthermore, tiopronin or coenzyme A modified Au NPs demonstrate excellent solubility in water (Templeton 1999). Subsequent association with metal nanoparticles the intrinsic properties of biomolecules can be changed. Recently it has been shown through SurfaceEnhanced Resonance Raman (SERR) spectroscopic studies that vibrations of the biologically active prosthetic heme groups of myoglobin or hemoglobin are selectively enhanced relative to the vibrational modes characteristic of the protein backbone following their adsorption on metal NPs (Bizzarri and Cannistraro 2002).

\section{Applications of metal nanoparticles}

In the ever expanding field of nanomaterial research, metal nanoparticle received particular attention due to their wide application in catalysis, electronics, sensing, photonics, environmental cleanup, imaging, and drug delivery (Guo et al. 2005, Daniel and Astruc 2004, Huang et al. 2007).

\subsection{Catalysis}

The application of nanoparticles as catalysts is a rapidly growing field in nanoscience and technology. The properties of noble metal nanoparticles make them ideal materials for nanocatalysis, where reaction yield and selectivity are dependent on the nature of the catalyst surface. Compared to bulk materials, nanoparticles have high surface-area-to volume ratio and thus found to exhibit higher turnover frequencies. The catalytic activity of $\mathrm{Au}, \mathrm{Ag}$ and $\mathrm{Pt}$ in the decomposition of $\mathrm{H}_{2} \mathrm{O}_{2}$ to oxygen is well known. Additionally they also catalyze luminal- $\mathrm{H}_{2} \mathrm{O}_{2}$ systems. It was observed that the chemiluminoscence emission from the luminal- $\mathrm{H}_{2} \mathrm{O}_{2}$ system was greatly enhanced by addition of Ag colloid (Guo, et al. 2008). The catalytic application of $\mathrm{Ag}$ in oxidation of ethylene to ethylene oxide and methanol to formaldehyde is also the most popular.

More interestingly, the nanoparticles shows shaped controlled catalytic activity. The shape-controlled catalytic properties have recently been observed in benzene hydrogenation by Pt catalyst (Brown 1997). Among different Pt nanocrystals, (cubes, tetrahedra, and spheres) tetrahedral nanocrystals, completely bound by $\{111\}$ crystal facets, exhibited highest catalytic activity whereas cubic nanocrystals exhibit the lowest activity (Fig. 7). However, it is not clearly understood whether this observation is truly a shape-dependent effect, as in solution the surface reconstruction and shape changes of NPs is evident. To study the dynamics of adsorbates on solution phase nanocrystalline 
structures is required for direct surface measurements analogous to those commonly used for single-crystalline studies.
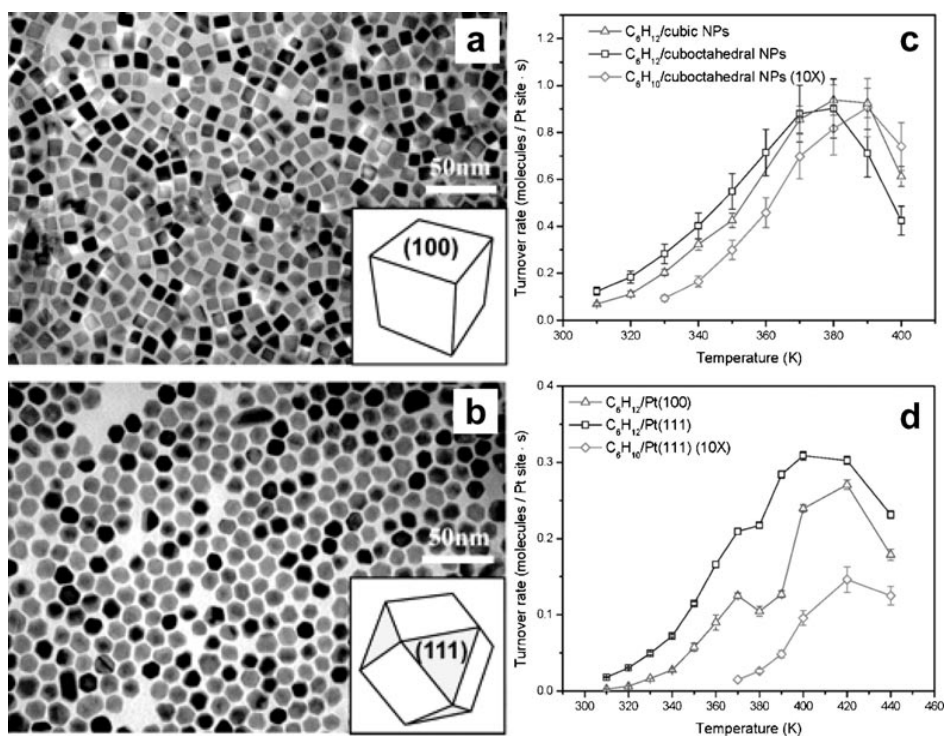

Fig. 7. Shape-controlled Pt nanocrystals show catalytic selectivity for benzene hydrogenation. The turnover rate for films of surfactant-stabilized $\mathrm{Pt} \mathrm{A}$ ) cubes and B) cuboactahedra, shown in these TEM images, were measured. C) Cubic nanocrystals are selective for cyclohexane, while cuboctahedra exhibit activity for both cyclohexane and cyclohexene. These results are consistent with the selectivity exhibited by single-crystalline Pt surfaces, shown in (D). Nat. Biotech. 1997, 15, 269.

Among other metal catalysts, Au has potentially more advantages is due to lower cost and greater stability. Au is being substantially cheaper and considerable more plentiful then Pt. AuNP less than $5 \mathrm{~nm}$ supported on base metal oxide or carbon demonstrated very high activity (Hvolbeck et al., 2007). High activity of AuNP for the oxidation many compounds, particularly $\mathrm{CO}$ and trimethylamine are also observed. AuNP based gas sensors have recently been developed for detecting a number of gases, including $\mathrm{CO}$ and NOx (Thompson 2007). Very recently Zeng et al. (2010) also demonstrated shape controlled catalytic activity of AuNPs for well known $p$-nitrophenol reduction in presence of sodium borohydride. Gold nanoboxes among other nanostructure (nanocages, and solid nanoparticles) have highest catalytic activity. The good intrinsic electrical connection across the entire surface of an Au nanocage makes it a much better catalyst than small Au solid nanoparticles for the redox reaction.

\subsection{Biological application of metal nanoparticles}

The application of metal nanoparticles in biological science showed very rapid progess the past decades is in the area of labelling, delivery, heating, and sensing. The SPER optical properties of colloidal AuNPs directed towards recent biomedical applications with an emphasis on cancer diagnostics and therapeutics. 


\subsubsection{Labelling}

For labelling, electron absorbing properties of the metal nanoparticles are exploited to generate contrast. The AuNPs strongly absorb electrons, thus make them suitable as a as a contrasting agent in TEM. Besides, nanoparticles have the same size domain as proteins that make nanomaterials suitable for bio tagging or labelling (Sperling et. 2008). Due to their small size and functionalising properties, i.e. with antibodies (immunostaining), AuNPs provide extremely high spatial resolution and applied in many labelling applications (Salata 2004). Additionally optical detection techniques are wide spread in biological research because of change of their optical or fluoresce properties. The formations of nanobiomaterials construct are schematically presented below (Fig. 8).

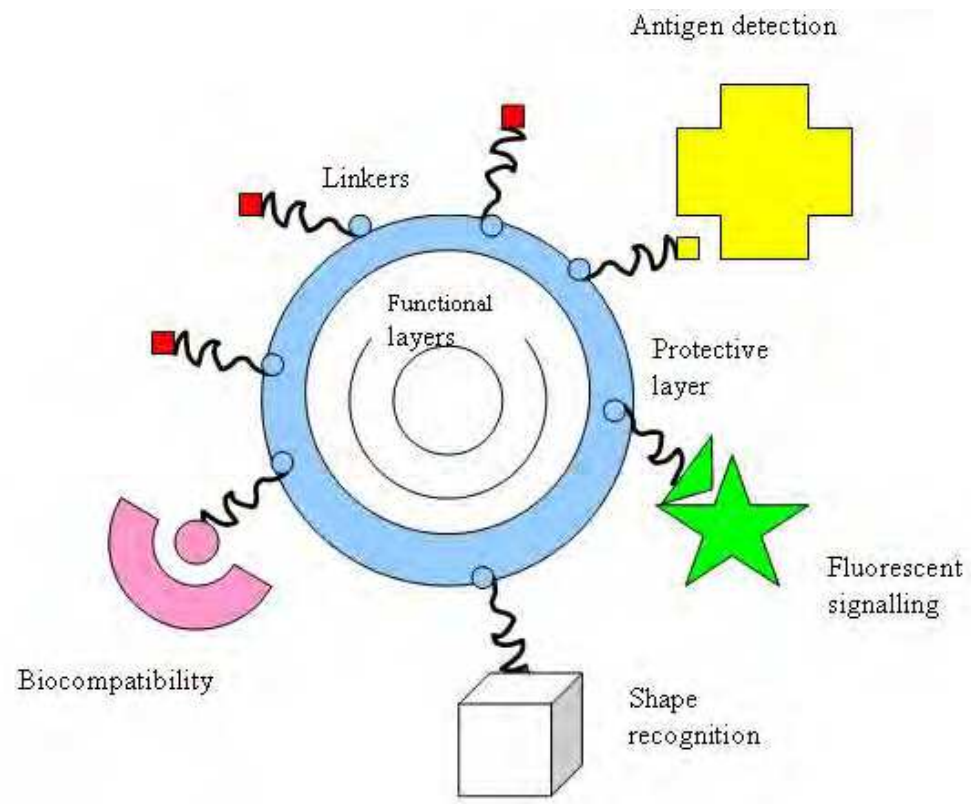

Fig. 8. Schematic presentation of application of nanoparticles in medical or biological problems. J. Nanobiotechnol. 2004, 2, 3.

Similarly, the particles' optical properties- strong absorption, scattering and especially plasmon resonance- make them of value for a large variety of light-based techniques including combined schemes such as photothermal or photo-acoustic imaging. In addition, AuNP can be radioactively-labelled by neutron activation, which allows for very sensitive detection, and used as an x-ray contrast agent.

\subsubsection{Sensors}

Metal nanoparticles can also be used as sensors. The optical and electronic sensing of biomaterials on surfaces is a common practice in analytical biochemistry. Thus, the immobilization of biomolecule-NP conjugates on surfaces provides a general route for the development of optical or electronic biosensors. Metal NPs such as Au or Ag NPs exhibit plasmon absorbance bands in the visible spectral region that are controlled by the size of the respective particles. Their optical properties can change upon binding to certain molecules, 
allowing the detection and quantification of analytes (Huo 2007). The absorption spectra of AuNP change drastically when several particles come close to each other. Numerous studies on the labelling of bioassays and the staining of biological tissues by metal particles as a means to image and visualize biological processes have been reported. The spectral shifts which originate from adjacent or aggregated metal nanoparticles, such as Au NPs, are of increasing interest in the development of optical biosensors based on biomolecule-NP hybrid systems. As an example, NPs that were functionalized with two kinds of nucleic acid, which were complementary to two segments of an analyzed DNA, were hybridized with the analyzed DNA. This led to the aggregation of the NPs and to the detection of a red shifted interparticle plasmon absorbance of the nanoparticle aggregate.

\subsubsection{Drug delivery}

Because of nontoxicity and nonimmunogenicity AuNPs is ideal for preparation of drugdelivery scaffold. Functionalization property of AuNP also makes it an excellent potential vehicle for the drug delivery. Functionalized AuNP represent highly attractive and promising candidates in the applications of drug delivery. Hamad-Schifferli (2008) groups recently developed druge delivery system AuNPs and infrared light. This delivery system released multiple drugs in a controlled fashion. They demonstrated that nanoparticles of different shapes respond to different infrared wavelengths. For example, nanobones and nanocapsules melt at light wavelengths of 1,100 and $800 \mathrm{~nm}$, respectively. Thus excitation at one wavelength could selectively melt one type of $\mathrm{Au}$ nanorods and selectively release one type of DNA strand.

Brown et al. (2010) also reported AuNPs for the improved anticancer drug delivery of the active component of oxaliplatin. Naked AuNPs were functionalized with a thiolated poly(ethylene glycol) (PEG) monolayer capped with a carboxylate group. [Pt $(1 R, 2 R-$ diaminocyclohexane) $\left.\left(\mathrm{H}_{2} \mathrm{O}\right)_{2}\right]_{2} \mathrm{NO}_{3}$ was added to the PEG surface and yielding a supramolecular complex with drug molecules. The cytotoxicity, drug uptake, and localization in the A549 lung epithelial cancer cell line and the colon cancer cell lines HCT116, HCT15, HT29, and RKO were examined for platinum-tethered nanoparticles. The platinum-tethered nanoparticles showed significant improvement in cytotoxicity than oxaliplatin alone in all of the cell lines and an unusual ability to penetrate the nucleus in the lung cancer cells.

\subsubsection{Cancer therapy}

Nanotechnology is one of the most popular research areas, especially with regard to biomedical applications. Nanoparticles have very good opportunity in the form of targeted drug therapies (Ghosh at al. 2008). Nanoparticles also carry the potential for targeted and time-release drugs. A potent dose of drugs could be delivered to a specific area but engineered to release over a planned period to ensure maximum effectiveness and the patient's safety. The strong light absorbing properties of AuNPs makes it suitable as heatmediating objects; the absorbed light energy is dissipated into the surroundings of the particles', generating an elevated temperature in their vicinity. This effect can be used to open polymer microcapsules, for example, for drug delivery purposes and even destroy the cancerous cells. The nanoparticles are functionalised with antibody specific to the cancerous cells. The functionalized nanoparticles specifically bind with the targeting cells, which was then killed by hyperthermal therapy through heating the particle-loaded tissue. However, for such in vivo applications, the potential cytotoxicity of the nanoparticles might become an issue and should be investigated with care. Due to biocompaticbility, hyperthermal activity 
activity AuNPs find wide application now a days in killing of malignant cancerous cells (Dickerson et al. 2008). Recently, Melancon et al. (2008) demonstrated destruction of cancerous cell by photothermal effect of AuNPs (Fig. 9). The hollow gold nanoshells (HAuNS; average diameter, $\sim 30 \mathrm{~nm}$ ) was covalently attached to monoclonal antibody directed to the epidermal growth factor receptor (EGFR). The resulting anti-EGFR-HAuNS exhibited excellent colloidal stability and efficient photothermal effect in the near-infrared region. Anti-EGFR-HAuNS then bound in EGFR-positive A431 tumor cells. Irradiation of A431 cells treated with anti-EGFR-HAuNS with near-infrared laser resulted in selective destruction of these cells.
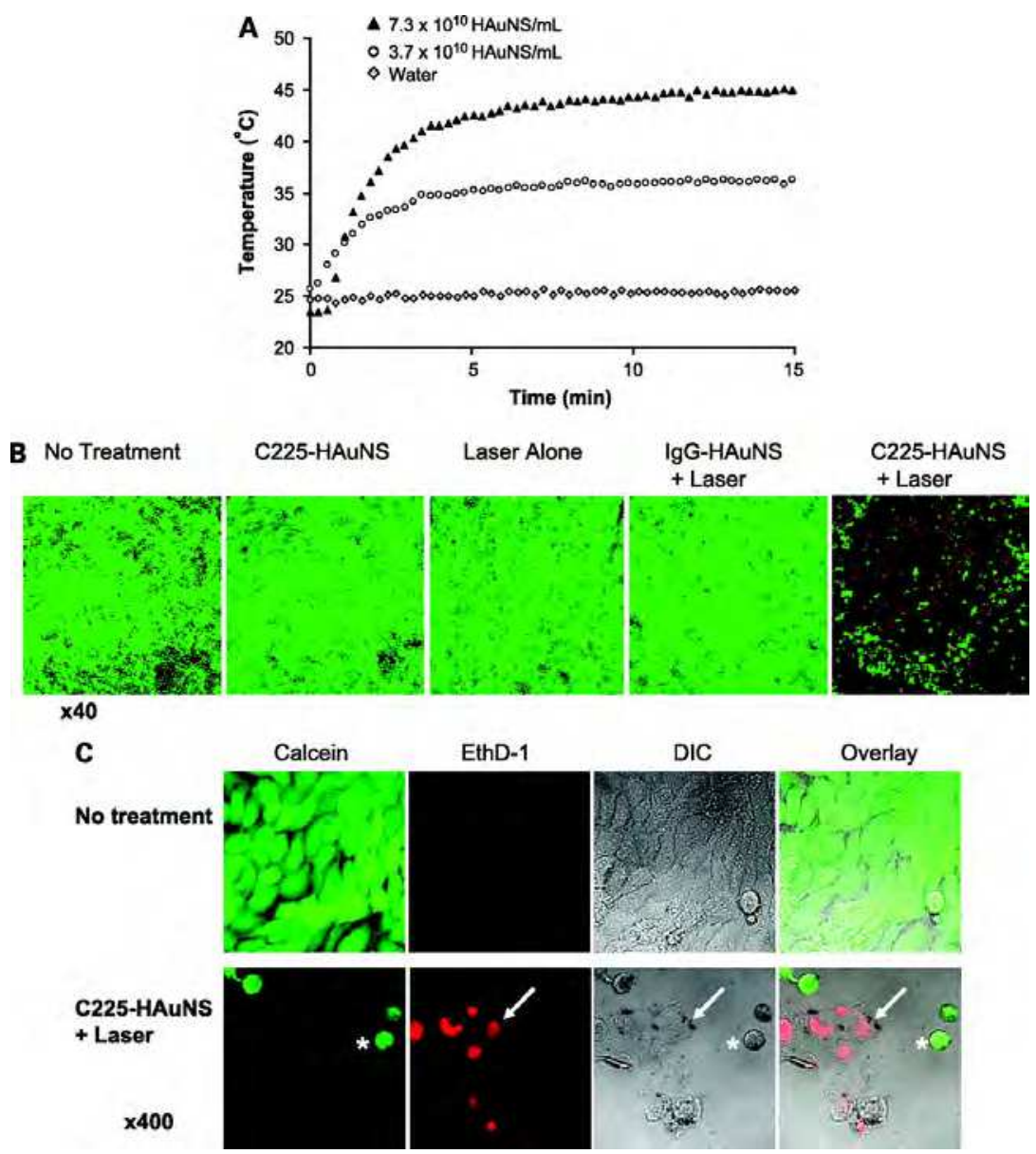

Fig. 9. A, heating of aqueous C225-HAuNS solutions exposed to NIR light centered at 808 $\mathrm{nm}$ at $8 \mathrm{~W} / \mathrm{cm}^{2}$. B, cell viability after various treatments. Cells retained normal morphology with no apparent death observed (stained green with calcein $\mathrm{CM}$ ) when cells were not treated or treated with C225-HAuNS alone, NIR laser alone, or nontargeted IgG-HAuNS plus NIR laser. In contrast, most cells were dead after treatment with C225-HAuNS plus NIR laser. Dead cells were labeled red with EthD-1. Mol. Cancer. Ther. 2008, 7, 1730-1739. 
AuNPs has also been applied to amplify the biorecognition of the anticancer drug (Shen et al. 2008). Dacarbazine [5-(3, 3-dimethy-1-triazenyl) imidazole-4-carboxamide; DTIC] is a commonly used anticancer drug. AuNPs were stabilized by PPh3 with negative charge. The oxidized DTIC is positive charged. Thus, DTIC could be easily assembled onto the surface of AuNPs. The specific interactions between anticancer drug DTIC and DNA or DNA bases were facilitated by AuNPs.

\subsection{Environmental cleanup}

Although MNPs are increasingly being employed in different emergent areas, their use in environmental biotechnology is still limited. One of the key environmental challenges is the contamination of water bodies by different chemicals due to diverse anthropogenic and industrial activities. The most interesting application of MNPS is purification of drinking water contaminated with heavy metals and pesticides. Current limitations in removal of heavy metals have been tried to overcome through adsorption process on MNPs due to alloy formation. Au and mercury exist in several phases such as $\mathrm{Au}_{3} \mathrm{Hg}$, $\mathrm{AuHg}$, and $\mathrm{AuHg}_{3}$. The interaction of AgNPs with $\mathrm{Hg}^{+2}$ ions was investigated because enhanced ability of $\mathrm{Ag}$ to form alloy in different phases. It was found that the surface plasmon of AgNPs blue shifted along with a decrease in the intensity, immediately after the addition of $\mathrm{Hg}^{+2}$ ions (Bootharaju and Pradeep 2010). Partial oxidation of AgNPs to silver ions is responsible for the decrease in intensity. The shift is attributed to the incorporation of mercury into the AgNPs. The mercury nanoparticle solutions exhibited plasmon absorption band below 300 $\mathrm{nm}$. The $\mathrm{Hg}-\mathrm{Ag}$ alloy nanoparticles, prepared by simultaneous reduction with sodium borohydride, exhibited a plasmon in the region of 300-400 nm. The potential of AgNPs to reduce a number of heavy metals can also be looked at as a method to prepare alloy nanoparticles; e.g., Ag-Hg bimetallic nanoparticles. A demonstration of the galvanic etching for the preparation of alloy nanoparticles is illustrated through the preparation of $\mathrm{Pd}-\mathrm{Ag}$ and $\mathrm{Pt}$-Ag nanoparticles.

Recently colorimetric detections of heavy metals like arsenic, mercury, lead, etc., have also been tried by using MNPs. One of the important properties exhibited by functionalized MNPs surfaces is the detection of heavy metals. In one such method, heavy metal specific biomolecule functionalized AuNP can be utilized. An example of this approach is the interaction of metal ions with nucleotides: $\mathrm{Hg}^{+2}$ promoted formation of thymine-thymine base pairs (Ono and Togashi 2004). In a similar approach, ligands functionalized MNPs have been used for specific detection of metal ions. This ligand-metal ion complexation leads to observable optical changes at concentrations in the ppm level. Examples of such ligands are gallic acid $\left(\mathrm{Pb}^{+2}\right)$, cysteine $\left(\mathrm{Hg}^{+2}, \mathrm{Cu}^{+2}\right)$, and mercaptoundecanoic acid $\left(\mathrm{Pb}^{+2}, \mathrm{Cd}^{+2}, \mathrm{Hg}^{+2}\right)$. Carboxylate group modified surface of AuNP can be induced to aggregate in the presence of $\mathrm{Hg}^{+2}$ and pyridinedicarboxylic acid, which is manifested in the form of colorimetric response, fluorescence quenching and enhancement of hyper-Rayleigh scattering intensity (Huang et al. 2007, Darbha et al. 2008).

The removal of pesticides by MNPs is a new addition to this field. Among other contaminants, presence of pesticide residue in potable water above permissible limit is of great concern to public health. This happens due to indiscriminate use of pesticide, specially belonging to organophosphorus groups, in agricultural practices. It is essential to reduce the concentration of pesticide in potable water but difficult to achieve by conventional chemical methods due to wide variation of their chemical structures. To meet these environmental challenges, very recently researchers are focusing on the development of methods based on 
nanotechnology. Very recently, Das et al (2009). demonstrated adsorption of different organophosphorous pesticides AuNPs surface. AuNPs was synthesized on the surface of the $R$. oryzae mycelia in a single set. The AuNPs adsorbed on mycelia were then used for adsorption of different organophosphorous pesticides. Following adsorption of these pesticides the surface morphology conspicuously changed compared the unadsorbed nanomaterial (Fig. 10) as depicted from atomic force microscopic images.

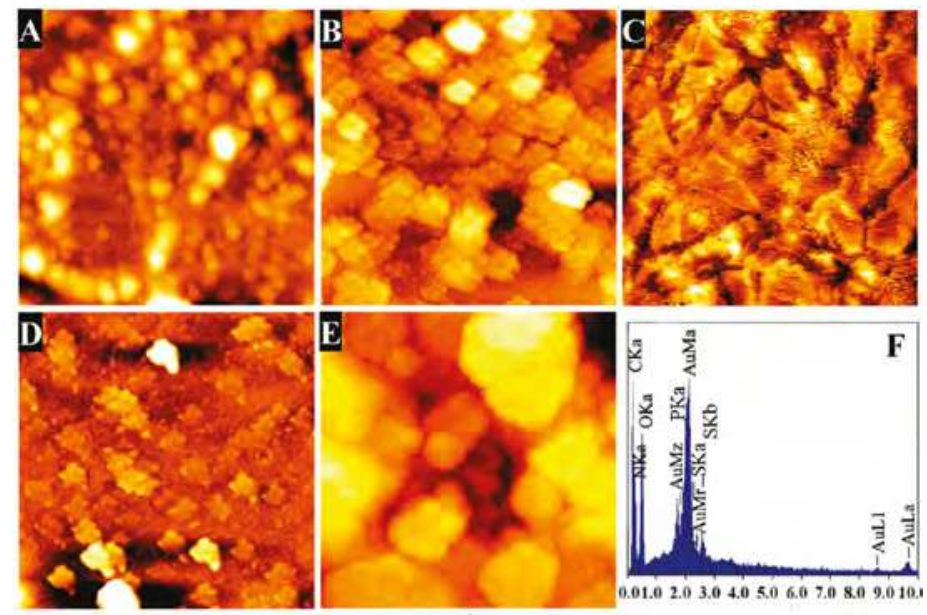

Fig. 10. AFM images of (A) the pristine nanogold bioconjugate (NGBC) and the (B) malathione, (C) parathione, (D) chlorpyrifos, and (E) dimethoate-adsorbed NGBC material. (F) EDXA spectrum of NGBC material after adsorption of organophosphorous pesticide. Langmuir 2009, 25(14), 8192-8199.

\section{Conclusions}

In this chapter, we provided an account of the chemical and biological methods for MNPs synthesis, as well as a short review of MNPs properties and of their most promising applications in biomedical devices, environmental processes, and chemical catalysis. From the considerations as outlined in this review, it emerges as biosynthesis represents a promising route for MNPs production. In fact, biosynthesis result in low energy use and environmental impact, with respect to conventional chemical synthesis methods. Further, the high specificity of biomolecules involved in the biosynthesis process may enable an efficient control of MNPs size and shape, whose tight control is critical to optimize MNPbased devices and applications. Biosynthetic MNPs have been observed in numerous fungal and bacterial species, and the molecular machinery needed for MNPs biosynthesis overlap significantly with that already developed and optimized for bioreduction and detoxification of soluble metals. However, most published studies deal with MNPs biosynthesis in viable microorganism, and the complexity of the system makes it difficult to identify the exact nature of the multiple biological agents responsible for the biosynthetic process. Further research with cell-free extract and biological fractions may lead to this identification and to a thorough understanding of the complex regulation underlying the expression of metalreducing agents. 
Future studies should also investigate the role of biological capping agents involved in MNPs biosynthesis on their cytotoxicity, catalytic and optoelectronics properties, ultimately to determine if biosynthetic MNPs are a viable commercial alternative to those synthesized through conventional chemical process.

\section{References}

Absar, A.; Satyajyoti, S.; Khan, M.I.; Rajiv, K.; Sastry, M. (2005). Extra-/intracellular biosynthesis of gold nanoparticles by an alkalotolerant fungus, Trichothecium sp., J. Biomedical Nanotechnnol. 1, 47-53

Ahmad, A.; Mukherjee, P.; Senapati, S.; Mandal, D.; Khan, M.I.; Kumar, R.; Sastry, M. (2003) Extracellular biosynthesis of silver nanoparticles using the fungus Fusarium oxysporum. Colloids Surf B Biointerfaces 28, 313-318

Andrievski, R.A.; Glezer. A.M. (2000). Size effects in Properties of Nanomaterials. Elsevier Science Ltd. 44, 1621-1623.

Anstas, P.T.; Warner, J.C. (1998). Green Chemistry: Theory and Practice, Oxford University Press, New York.

Beveridge, T.J.; Murray, R.G.E. (1980). Site of metal deposition in the cell wall of Bacillus subtilis. J. Bacteriol. 141, 876-887

Bigall, N.C.; Reitzig, M.; Naumann, W.; Simon, P.; van Pée, K.H.; Eychmüller. A. (2008). Fungal Templates for Noble-Metal Nanoparticles and Their Application in Catalysis. Angew. Chem. Int. Ed., 47 7876-7879

Birringer, R.; Gleiter, H.; Klein, H.P.; Marquardt P. (1984). Nanocrystalline materials, an approach to a novel solid structure with gas like disorder. Phys. Lett. A 102, 365

Bizzarri, A.R.; Cannistraro, S. (2002). Appl. Spectrosc. 56, 1531-1537

Bootharaju, M.S.; Pradeep, T. (2010). Uptake of toxic metal ions from water by naked and monolayer protected silver nanoparticles: An X-ray photoelectron spectroscopic investigation. J. Phys. Chem. C 114, 8328-8336

Brown, S. (1997). Nat. Biotech. 15, 269

Brown, S.D.; Nativo, P.; Smith, J.-A.; Stirling, D.; Edwards, P.R.; Venugopal, B.; Flint, D.J.; Plumb, J.A.; Graham, D.; Wheate. N.J. (2010). Gold Nanoparticles for the Improved Anticancer Drug Delivery of the Active Component of Oxaliplatin. J. Am. Chem. Soc. 132, 4678-4684

Brust. M.; Walker, M.; Bethell, D.; Schiffrin ,D. J.; Whyman, R. (1994). Synthesis of Thiolderivatised Gold Nanoparticles in a Two-phase Liquid-Liquid System. Chem. Commun. 7, 801.

Burda, C.; Chen, X.; Narayanan, R.; El-Sayed M.A. (2005). Chemistry and Properties of Nanocrystals of Different Shapes. Chemical Rev. 105, 1025-1102

Cha, J.N.; Shimizu, K.; Zhou, Y.; Christiansen, S.C.; Chmelka, B.F.; Stucky, G.D.; Morse, D.E. (1999). Silicatein filaments and subunits from a marine sponge direct the polymerization of silica and silicones in vitro. Proc. Natl. Acad. Sci USA. 96, 361-365

Chaki, N.K.; Sundrik, S.G.; Sonawane, H.R.; Vijayamohanan, K. (2002). J. Chem. Soc. Chem. Commun. 76.

Dahl, J.A.; Maddux, B.L.S.; Hutchison. J.E. (2007). Toward Greener Nanosynthesis. Chem. Rev. 107, 2228-2269 
Daniel, M.-C.; Astruc, D. (2004). Gold Nanoparticles: Assembly, Supramolecular Chemistry, Quantum-Size-Related Properties, and Applications Toward Biology, Catalysis, and Nanotechnology. Chem. Rev. 104, 293-346

Darbha, G.K.; Singh, A.K.; Rai, U.S.; Yu, E.; Yu, H.; Ray, P.C. (2008). J. Am. Chem. Soc.130, 8038

Das, S.K.; Das, A.R.; Guha. A.K. (2009). Gold Nanoparticles: Microbial Synthesis and Application in Water Hygiene Management. Langmuir 25, 8192-8199

Das, S.K.; Marsili, E. (2010). A green chemical approach for the synthesis of gold nanoparticles: characterization and mechanistic aspect. Rev. Environ. Sci. Biotechnol. 9, 199-204

Dickerson, B.E.; Dreaden, C.E.; Huang, X., El-Sayed, H. I.; Chu, H.; Pushpanketh, S.; McDonald, H.I., El-Sayed, A.M. (2008). Gold nanorod assisted near-infrared plasmonic photothermal therapy (PPPT) of aquamous cell carcinoma in mice. Cancer Lett. 269, 57-66

Duran, N.; Marcato, D.P.; Alves, L.O.; De Souza, G.; Esposito, E. (2005). Mechanical aspect of biosynthesis of silver nanoparticles by several Fusarium oxysporum strains. J. Nanobiotechnol. 3, 8-15

El-Sayed, M.A. (2001). Some Interesting Properties of Metals Confined in Time and Nanometer Space of Different Shapes. Acc. Chem. Res., 34, 257-264

Faivre, D.; Schüler, D. (2008). Magnetotactic Bacteria and Magnetosomes. Chem. Rev. 108, $4875-4898$

Faraday, M. (1857). Experimental relations of gold (and other metals) to light. Phil. Trans. Roy. Soc. London 147, 145-181

Frens, G. (1972). Particle size and sol stability in metal colloids. Colloid Polym. Sci. 250, 736741

Gacoin, T.; Malier, L.; Boilot, J.-P. (1997). Sol-gel transition in CdS colloids J. Mater. Chem. 7, 859-860

Ghosh, P.; Han, G.; De, M.; Kim, K.C.; Rotello, M.V. (2008). Gold nanoparticles in delivery applications. Advanced Drag Delivery Rev. 60, 1307-1315

Guo, J-Z.; Cui, H.; Zhou, W.; Wang, W. (2008). Ag nanoparticle-catalyzed chemiluminescent reaction between luminal and hydrogen peroxide. J. Photochem. Photobiol., A Chem. 193, 89-96

Guo, R.; Song, Y.; Wang, G.; Murray, R.W. (2005). Does Core Size Matter in The Kinetics of Ligand Exchanges of Monolayer-Protected Au Clusters? J. Am. Chem. Soc. 127, 27522757

"Hall Petch Relationship, The." 25 Apr 2005. http://www.matsci.ucdavis.edu/MatSciLT/EMS-174L/Files/HallPetch.pdf

He, S.; Guo, Z.; Zhang, Y.; Zhang, S.; Wang, J.; Gu, N.; (2007). Biosynthesis of gold nanoparticles using the bacteria Rhodopseudomonas capsulate. Materials Latter 61, 3984-3987

Henglein, A. (1998). Chem. Mater. 10, 444

Huang, C.C.; Yang, Z.; Lee, K. H.; Chang, H. T. (2007). Synthesis of Highly Fluorescent Gold Nanoparticles for Sensing Mercury(II) Angew. Chem., Int. Ed. 46, 6824-6828

Huang, C.-C.; Yang, Z.; Lee, K.-H.; Chang, H.-T. (2007). Angew. Chem. Int. Ed. 46, 6824

Huo, Q. (2007). A perspective on bioconjugated nanoparticles and quantum dots. Colloids Surfaces B: Biointerfaces 59, 1-10. 
Husseiny, I.M.; El-Aziz, A.M.; Badr, Y.; Mahmoud, A.M. (2007). Biosynthesis of gold nanoparticles using Pseudomonas aeruginosa, Spectrochimica Acta Part A 67, 1003-1006

Hvolbek, B.; Janssens, W.V.T.; Clausen, S.B.; Falsig, H.; Christensen, H.C.; Norskov, K.J. (2007). Catalytic activity of Au nanoparticles. Nano Today 2, 14-18

Justus, B.L.; Tonucci, R.J.; Berry, A.D. (1992). Discovery and development of antibodies. Appl. Phys. Lett. 61, 3151.

Kalathil, S.; Lee, J.; Cho, M.H. (2011). Electrochemically active biofilm-mediated synthesis of silver nanoparticles in water. Green Chem. DOI: 10.1039/c1gc15309a

Kalimuthu, K.; Babu, S.R.; Venkataraman, D.; Bilal, M.; Gurunathan, S. (2008). Biosynthesis of silver nanoparticles by Bacillus licheniformis, Colloids Surfaces B: Biointerfaces 65, 150-153

Kalishwaralal, K.; Deepak, V.; Ram Kumar Pandian, S.; Gurunathan, S. (2009). Biosynthesis of gold nanocubes from Bacillus lichemiformis. Bioresour. Technol. 100, 5356-5358

Kalishwaralal, K.; Deepak, V.; Ramkumarpndian, S.; Nellaiah, H.; Sangiliyandi, G. (2008). Extracellular biosynthesis of silver nanoparticles by the culture supernatant of Bacillus licheniformis. Materials Letters 62, 4411-4413

Kang, Il-S.; Kang, M.-H.; Lee, E.; Seo H.-S.; Ahn. C.W. (2011). Facile, hetero-sized nanocluster array fabrication for investigating the nanostructure-dependence of nonvolatile memory characteristics. Nanotechnol. 22, 254018 doi: 10.1088/0957$4484 / 22 / 25 / 254018$

Kathiresan, K.; Manivannan, S.; Nabeel, A.M.; Dhivya, B. (2009). Studies on silver nanoparticles synthesized by a marine fungus Penicillum fellutanum isolated from coastal mangrove sediment, Colloids Surfaces B: Biointerfaces 71, 133-137

Katz, E.; Willner, I. (2004). Integrated Nanoparticle-Biomolecule Hybrid Systems: Synthesis, Properties, and Applications. Angew. Chem. Int. Ed. 43, 6042-6108

Kelly, K.L.; Coronado, E.; Zhao, L.L.; Schatz, G.C. (2003). J. Phys. Chem. B 107, 668-677.

Klaus, T.; Joerger, R.; Olsson, E.; Granqvist, C.-G. (1999). Silverbased crystalline nanoparticles, microbially fabricated. Proc. Natl. Acad. Sci. USA 96, 13611-13614

Konishi, Y.; Nomura, T.; Tsukiyama, T.; Saitoh, N. (2004). Microbial preparation of gold nanoparticles by anaerobic bacterium. Trans. Mater. Res. Soc. Jpn. 29, 2341-2343

Law, N.; Ansari, S.; Livens, F.R.; Renshaw, J.C.; Lloyd. J.R. (2008). Formation of Nanoscale Elemental Silver Particles via Enzymatic Reduction by Geobacter sulfurreducens. Appl. Environ. Microbiol. 74, 7090-7093

Lowenstam, H.A. (1981). Minerals formed by organisms. Nature 211, 1126-1131

Mafuné, F.; Kohno, J.; Takeda, Y.; Kondow. T. (2001). Formation of Gold Nanoparticles by Laser Ablation in Aqueous Solution of Surfactant. J. Phys. Chem. B 105 22, 5114-5120

Maier, S.A. (2007). Plasmonics: Fundamentals and Applications. Springer Science+Business Media LLC.

Maiti, M.; et al. (2005). Effect of Carbon Black on Properties of Rubber Nanocomposites. Wiley InterScience.

Mandal, D.; Bolander, M.E.; Mukhopadhyay, D.; Sarkar, G.; Mukherjee, P. (2006). The use of microorganisms for the formation of metal nanoparticles and their application. Appl. Microbiol. Biotechnol. 69, 485-492

Mann, S. (1993) Molecular tectonics in biomineralization and biomimetic materials chemistry. Nature 365, 499-505 
Melancon, M.P.; Lu, W.; Yang, Z.; Zhang, R.; Cheng, Z.; Elliot, A.M.; Stafford, J.; Olson, T.; Zhang, J.Z.; Li, C. (2008). In vitro and in vivo targeting of hollow gold nanoshells directed at epidermal growth factor receptor for photothermal ablation therapy. Mol. Cancer. Ther. 7, 1730-1739

Mergeay, M.; et al. (2003) Ralstonia metallidurans, a bacterium specifically adapted to toxic metals: Towards a catalogue of metal-responsive genes. FEMS Microbiol. Rev. 27, 385-410

Mie, G. (1908). Ann. Phys. 25, 377-445

Mukherjee, P.; Ahmad, A.; Mandal, D.; Senapati, S.; Sainkar, S.R.; Khan, M.I.; Ramani, R.; Parischa, R.; Ajayakumar, P.V.; Alam, M.; Sastry, M.; Kumar, R. (2001a). Bioreduction of AuCl4- ions by the fungus, Verticillium sp. and surface trapping of the gold nanoparticles formed. Angew. Chem. Int. Ed. 40, 3585-3588

Mukherjee, P.; Ahmad, A.; Mandal, D.; Senapati, S.; Sainkar, S.R.; Khan, M.I.; Parischa, R.; Ajayakumar, P.V.; Alam, M.; Kumar, R.; Sastry, M. (2001b). Fungus mediated synthesis of silver nanoparticles and their immobilization in the mycelia matrix: a novel biological approach to nanoparticle synthesis. Nano Lett. 1, 515-519

Murphy, C.J.; Orendorff. C.J. (2005). Alignment of gold nanorods in polymer composites and on polymer surfaces. Adv. Mater. 17, 2173-2177

Murphy, C.J.; Sau, T.K.; Gole,A.M.; Orendorff, C.J.; Gao, J.; Gou, L.; Hunyadi, S.E.; Li, T. (2005). Anisotropic Metal Nanoparticles: Synthesis, Assembly, and Optical Applications. J. Phys. Chem. B 109, 13857-13870

Olshavsky, M.A.; Allcock, H.R. (1997). Small scale system for in-vivo drug delivery. Chem. Mater, 9, 1367.

Ono, A.; Togashi, H. (2004). Angew. Chem. Int. Ed. 43, 4300

Pérez-Tijerina, E.; Gracia-Pinilla, M.A.; Mejía-Rosales. S.; Ortiz-Méndez, U.; Torres .A.; JoséYacamán, M. (2008). Highly size-controlled synthesis of Au/Pd nanoparticles by inert-gas condensation. Faraday Discuss.138, 353-362

Philip, D. (2009). Biosynthesis of Au, Ag and Au-Ag nanoparticles using edible mushroom extract, Spectrochemia Acta Part A 73, 374-381

Posfai, M.; Moskowitz, B. M.; Arato, B.; Schuler, D.; Flies, C.; Bazylinski, D. A.; Frankel, R.B. (2006). Properties of intracellular magnetite crystals produced by Desulfovibrio magneticus strain RS-1. Earth Planet. Sci. Lett. 249, 444-455

Poulsen, N.; Sumper, M.; Kröger, N. (2003). Biosilica formation in diatoms: Characterization of native silaffin-2 and its role in silica morphogenesis. Proc. Natl. Acad. Sci USA. 100, 12075-12080

Raffi, M.; Rumaiz, A.K.; Hasan, M.M.; Shah. S.I. (2007). Studies of the growth parameters for silver nanoparticle synthesis by inert gas condensation. J. Mater. Res. 22, 3378- 3384

Reith, F.; Etschmann, B.; Gross, C.; Moors, H.; Benotmane, M.A.; Monsieurs, P.; Grass, G.; Doonan, C.; Vogt, S.; Lai, B.; Martinez-Criado, G.; George, G.N.; Nies, D.H.; Mergeay, M.; Pring, A.; Southam, G.; Brugger, J. (2009). Mechanisms of gold biomineralization in the bacterium Cupriavidus metallidurans. Proc. Natl. Acad. Sci USA. 160, 17757-17762

Ren, W., Ai, Z.jJia, F.; Zhang, L.; Fan, X.; Zou, Z. (2007). Low temperature preparation and visible light photocatalytic activity of mesoporous carbon-doped crystalline $\mathrm{TiO}_{2}$. Appl. Catal. B $69,138-144$ 
Roduner, E. (2006). Size matters: Why Nanomaterials are Different. Chem. Soc. Rev. 35, 583592

Rosemary, M.J.; Pradeep. T. (2003). Solvothermal synthesis of silver nanoparticles from thiolates. J. Colloid Interface Sci. 268, 81-84

Sakaguchi, T.; Burgess, J.G.; Matsunaga, T. (1993). Magnetite formation by a sulphatereducing bacterium. Nature $365,47-49$

Salata, O.V. (2004). Applications of nanoparticles in biology and medicine. J. Nanobiotechnol. 2,3

Sankaran, V.; Yue ,J.; Cahen, R.E.; Schrock, R.R. Silbey, R.J. (1993). Advanced drug delivery advices. Chem. Mater, 5: 1133.

Sastry, M.; Ahmad, A.; Khan, I.M.; Kumar, R. (2003). Biosynthesis of metal nanoparticles using fungi and actinomycete, Current Sci. 85, 2, 162-170

Scott, D.; Toney, M.; Muzikár, M. (2008). Harnessing the Mechanism of Glutathione Reductase for Synthesis of Active Site Bound Metallic Nanoparticles and Electrical Connection to Electrodes. J. Am. Chem. Soc. 130, 865-874

Shaligram, S.N.; Bule, M.; Bhambure, R.; Singhal, S.R.; Singh, K.S.; Szakacs, G.; Pandey, A.; (2009). Biosynthesis of silver nanoparticles using aqueous extract from the compactin producing fungal, Process Biochem. 44, 939-943

Shen, Q.; Wang, X.; Fu, D. (2008). The amplification effect of functionalized gold nanoparticles on the binding of cancer drug decarbazine to DNA and DNA bases. Applied Surface Sci. 255, 577-580

Shukla, S.; Seal, S. (1999). Cluster size effect observed for gold nanoparticles synthesized by sol-gel technique as studied by X-ray photoelectron spectroscopy. NanoStruct. Mater. 11, 1181-1193,

Southam, G.; Beveridge, T.J. (1994). The in vitro formation of placer gold by bacteria. Geochim. Cosmochim. Acta 58, 4527-4530

Southam, G.; Saunders, J.A. (2005). The geomicrobiology of ore deposits. Econ Geol 100, 1067-1084

Sperling, A.R.; Gil, R.P.; Zhang, F.; Zanella, M.; Parak, J.W. (2008). Biological application of gold nanoparticles. Chem. Soc. Rev. 37, 1896-1908

Tao, A.R.; Habas, S.; Yang, P. (2008). Shape Control of Colloidal Metal Nanocrystals. Small 4, 310-325

Templeton, A.C.; Chen, S.; Gross, S.M.; Murray, R.W. (1999). Langmuir 15, 66-76

Thompson, T.D. (2007). Using gold nanoparticles for catalysis. Nano Today, 2, 40-43

Turkevich, J.; Stevenson, P.C.; Hillier, J. (1951). A study of the nucleation and growth processes in the synthesis of colloidal gold. Discuss. Faraday. Soc. 11, 55-75

Wijaya, A.; Schaffer, S.B.; Pallares, I.G.; Hamad-Schifferli, K. (2008). ACS Nano 3, 80

Xie, .;, Lee, J.Y.; Wang, D.I.C.; Ting, Y.P. (2007). Identification of Active Biomolecules in the High-Yield Synthesis of Single-Crystalline Gold Nanoplates in Algal Solutions. Small 3, $672-682$

Yang, H.G.; Sun, C.H.; Qiao, S.H.; Zou, J.; Liu,G.; Smith, S.C.; Cheng, H.M.; Lu, G.Q. (2008). Anatase $\mathrm{TiO}_{2}$ single crystals with a large percentage of reactive facets. Nature 453, 638-641

Yuan, Y.; Fendler, J.; Cabasso, I. (1992). Therapeutics antibiotics. Chem. Mater. 4, 312.

Zeng, J.; Zhang, Q.; Chen, J.; Xia, Y. (2010). A Comparison Study of the Catalytic Properties of Au-Based Nanocages, Nanoboxes, and Nanoparticles. Nano Lett. 10, 30-35 


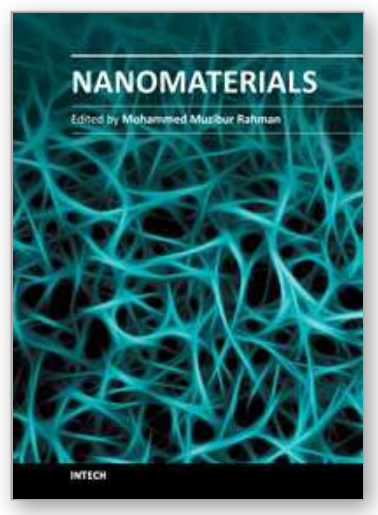

\author{
Nanomaterials \\ Edited by Prof. Mohammed Rahman
}

ISBN 978-953-307-913-4

Hard cover, 346 pages

Publisher InTech

Published online 22, December, 2011

Published in print edition December, 2011

The book "Nanomaterials" includes all aspects of metal-oxide nano-structures, nano-composites, and polymer materials instigating with materials survey and preparations, growth and characterizations, processing and fabrications, developments and potential applications. These topics have utilized innovative methods of preparation, improvement, and continuous changes in multidimensional ways. The innovative frontiers are branching out from time to time to advanced nanotechnology. It is an important booklet for scientific organizations, governmental research-centers, academic libraries, and the overall research and development of nano-materials in general. It has been created for widespread audience with diverse backgrounds and education.

\title{
How to reference
}

In order to correctly reference this scholarly work, feel free to copy and paste the following:

Sujoy K. Das and Enrico Marsili (2011). Bioinspired Metal Nanoparticle: Synthesis, Properties and Application, Nanomaterials, Prof. Mohammed Rahman (Ed.), ISBN: 978-953-307-913-4, InTech, Available from: http://www.intechopen.com/books/nanomaterials/bioinspired-metal-nanoparticle-synthesis-properties-andapplication

\section{INTECH}

open science | open minds

\section{InTech Europe}

University Campus STeP Ri Slavka Krautzeka 83/A 51000 Rijeka, Croatia Phone: +385 (51) 770447 Fax: +385 (51) 686166 www.intechopen.com

\section{InTech China}

Unit 405, Office Block, Hotel Equatorial Shanghai No.65, Yan An Road (West), Shanghai, 200040, China 中国上海市延安西路65号上海国际贵都大饭店办公楼405单元 Phone: +86-21-62489820

Fax: +86-21-62489821 
(C) 2011 The Author(s). Licensee IntechOpen. This is an open access article distributed under the terms of the Creative Commons Attribution 3.0 License, which permits unrestricted use, distribution, and reproduction in any medium, provided the original work is properly cited. 